\title{
Competitive Target Advertising and Consumer Data Sharing
}

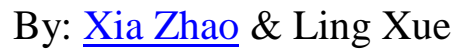

Zhao, Xia and Ling Xue. "Competitive Target Advertising and Consumer Data Sharing," Journal of Management Information Systems, 29(3), Winter 2012-2013, pp. 189-222.

This is an Accepted Manuscript of an article published by Taylor \& Francis in Journal of Management Information Systems in Winter 2012-2013, available online: http://dx.doi.org/10.2753/MIS0742-1222290306.

***:() Taylor \& Francis. Reprinted with permission. No further reproduction is authorized without written permission from Taylor \& Francis. This version of the document is not the version of record. Figures and/or pictures may be missing from this format of the document. $* * *$

\begin{abstract}
:
Advances in information technologies enable firms to collect detailed consumer data and target individual consumers with tailored ads. Consumer data are among the most valuable assets that firms own. An interesting phenomenon is that competing firms often trade their consumer data with each other. Based on a common-value all-pay auction framework, this paper studies the advertising competition between two firms that target the same consumer but are asymmetrically informed about the consumer value. We characterize firms' equilibrium competition strategies. The results show that better consumer information does not help the better-informed firm save the advertising expenditure but does enable it to reap a higher expected profit in competition. Sharing individual-level consumer data may soften the competition even though firms compete head-to-head for the same consumer. We also find that the better-informed firm may sell its data to its competitor but never voluntarily shares it with its competitor.
\end{abstract}

Keywords: advertising | all-pay auction | common-value auction | information asymmetry | information sharing | target marketing

Article:

Advances in consumer-tracking technologies enable firms, especially e-commerce firms, to collect a large amount of individual-level consumer data. For example, an investigation by the Wall Street Journal [2] indicates that the 50 most popular Web sites in the United States installed a total of 3,180 tracking files on a single computer. The tracking files, such as cookies, beacons, and video cookies, help firms record online behaviors of individuals, including specific pages visited, browsing trails from one site to another, searches made, and clickthroughs to specific content or ads. This data enables firms to estimate the value of consumers and target individual consumers with tailored ads. The market for target advertising is growing fast. Worldwide online target advertising spending is projected to exceed $\$ 2.6$ billion in 2014 [17].

investigation by the Wall Street Journal [2] indicates that the 50 most popular Web sites in the United States installed a total of 3,180 tracking files on a single computer. The tracking 
files, such as cookies, beacons, and video cookies, help firms record online behaviors of individuals, including specific pages visited, browsing trails from one site to another, searches made, and clickthroughs to specific content or ads. This data enables firms to estimate the value of consumers and target individual consumers with tailored ads. The market for target advertising is growing fast. Worldwide online target advertising spending is projected to exceed $\$ 2.6$ billion in 2014 [17].

The sharing of individual-level consumer data raises a question concerning the firm's competition: Why do firms share their valuable consumer data when they compete for consumers head-to-head? Extant literature has examined firms' incentives to share individual-level consumer data in various competitive settings (e.g., [9, 24, 30]). These studies are all under the premise that consumers have brand preferences that are exogenously given. The key insight is that sharing individual-level consumer information allows firms to better segment their consumers and develop differentiated pricing strategies. Each firm therefore focuses more on consumers preferring it and avoids aggressively competing for consumers preferring its competitor. However, the consumer behavior data collected online often reveals consumers' intent to purchase products in certain categories, rather than their brand loyalty. For example, consumer searches for airfares on price comparison Web sites often indicate that consumers have intent to purchase trips. This data does not necessarily reveal which brand consumers are loyal to [27]. The search data for products, rather than brands, can be used by competing brands to send target ads. Sharing this data enables competing brands to better learn and target the same set of consumers. In this regard, the competition should be intensified by consumer data sharing. It is therefore not clear why firms would like to share this data with competitors and whether the business model of consumer data exchange is viable.

This paper studies consumer data sharing in a setting where firms compete for consumers head-to-head using individual targeting. Departing from the existing literature $[9,24,30]$, we consider the case where consumers have no brand preference. What matters to firms is the consumer value. A valuable consumer has a higher consumption level and generates a higher revenue income to the firm (e.g., by spending more) than a nonvaluable consumer. Firms do not know a consumer's true value. However, each of them can draw signals about the consumer value from its individual-level consumer data. Firms have asymmetric information - one firm has better consumer data and hence can draw more accurate signals than the other. Firms compete for consumers by sending target ads based on their information about the consumer.

We use this model to examine several issues. The first issue concerns the equilibrium of the firm competition. If firms are not symmetrically informed about the consumer value, how should they spend in targeting this consumer in competition? The second issue concerns the impact of information asymmetry on the firms' advertising competition. How does information asymmetry influence firms' advertising spending? When information asymmetry decreases, are firms better off or worse off? The last issue concerns consumer data sharing. Does the betterinformed firm have an incentive to share or sell its consumer data to the less-informed firm? To what extent should the better-informed firm share/sell its data? The answers to these questions generate important managerial implications.

The key findings of this study are as follows. First, this paper characterizes the equilibrium of firms' competition in target advertising. It shows how firms' advertising spending and profitability are dependent on their information about the consumer value. The study illustrates that when consumers have no brand preference, information asymmetry essentially creates differentiation between the ex ante homogeneous firms and helps them avoid destructive 
competition. The analysis generates a counterintuitive result on the firms' spending in target advertising. Firms always spend the same amount, on average, in targeting a consumer despite their information difference. Better consumer information enables firms to focus their advertising spending on the more valuable consumers. Therefore, although the better-informed firm and the lessinformed firm incur the same level of expected expenditure in targeted advertising, the expected profit of the better-informed firm is higher than that of the less-informed firm. This finding provides an important insight on the role of consumer information in target advertisingbetter information does not necessarily help a firm save on their advertising expenditure; rather, it may help the better-informed firm improve the effectiveness of its target advertising.

Second, this paper characterizes how information asymmetry influences the firms' competition. Conventional wisdom may suggest that decreasing information asymmetry always intensifies the firms' competition in targeting consumers. However, our analysis indicates that this is not the case. We find that even when firms compete head-to-head, decrease in information asymmetry may dampen the competition under certain conditions. We characterize these conditions in this paper.

Third, this paper examines the firms' consumer data-sharing decisions. We find that the better-informed firm never gives away its data for free. The better-informed firm never directly benefits from the softened competition-its profit always decreases as the level of information asymmetry becomes lower. This result is in contrast to a key finding in the literature on individual targeting (e.g., [9]), which indicates that a firm is willing to voluntarily share its consumer information with its competitor. Even though voluntary sharing never occurs in this paper, the results show that the betterinformed firm is willing to sell its consumer data to its competitor. The study also finds that the degree of information sharing is dependent on the market condition that the better-informed firm perceives. When it is more likely for the betterinformed firm to receive a good signal on the consumer value and find the market more promising, the better-informed firm would like to sell more of its data to the competitor.

The rest of the paper is organized as follows. The next section reviews the literature. The third section outlines the model setup. The fourth section examines the equilibrium of firm competition in target advertising. The fifth section investigates consumer data sharing. Finally, the sixth section discusses the key managerial implications of this study and concludes the paper.

\section{Literature Review}

Our paper relates to the stream of information systems (IS) literature on price discrimination and product differentiation in e-commerce. Recent work in this stream examines how e-commerce firms may price-discriminate consumers using quality differentiation in digital products/services (e.g., $[4,20])$ or digital bundling (e.g., $[11,15])$. The availability of individual-level consumer data provides firms with more capability to tailor their prices and promotional offers. Firms tend to leverage such capability in competition. Therefore, the competition based on individual-level consumer information has also become a focus in the marketing literature (e.g., [8, 9, 24, 25, 34]) and the IS literature (e.g., [10, 28]). In the IS literature, for example, Mehra et al. [28] investigated the competitive upgrade discount pricing strategies based on consumer prior purchase behavior using a Hotelling model. Choudhary et al. [10] examined perfect price discrimination with knowledge of consumer values in a vertically differentiated duopolistic setting. The above studies focused mostly on the use of individual-level consumer information in competitive price discrimination. In our paper, we consider how firms use individual-level 
consumer information in target advertising competition. We also consider the issue of information sharing between firms when they have differentiated information about the consumers.

Target advertising has been analytically examined in different settings. For example, Esteban et al. [13] considered a monopolistic market where consumers have heterogeneous reservation prices. They found that by using target advertising, the monopolist advertises more to the consumers with higher reservation prices. In addition, the overall level of advertising is lower. Roy [33] studied a competitive market where two firms use advertising to target a group of consumers. He found that firms always target and sell to mutually exclusive market segments in which each firm acts as a purely local monopolist. Iyer et al. [21] studied target advertising in a competitive market where firms sell differentiated products to both customers with strong brand preferences and comparison shoppers. Target advertising enables firms to advertise less to comparison shoppers, creating differentiation and softening pricing competition. Chen and Stallaert [7] compared the price competition between advertisers using target advertising and using uniform advertising and found that behavior targeting can soften the advertisers' competition. In these studies, competing firms are always equally informed about consumers. Our paper, in contrast, studies target advertising competition between firms when they are asymmetrically informed about the consumer value.

This study also relates to the literature on information sharing. The informationsharing literature includes both the studies that examine vertical information sharing between supply chain partners (e.g., $[16,22,23])$ and the studies that examine horizontal information sharing between competing firms (e.g., [9, 14, 24, 30, 37, 38, 39]). Chen [6] provides a comprehensive review of the supply chain management literature on vertical information sharing. Our study focuses on horizontal information sharing. The traditional literature on horizontal information sharing has investigated the sharing of general demand information between competing firms (e.g., [14, 37, 38, 39]). More recent literature focuses on the sharing of individual-level consumer data (e.g., [9, 24, 30, 36]). This paper is closely related to the latter stream of literature (i.e., the sharing of individual consumer data). In this literature, Taylor [36] studied the trading of individual customer information between firms that sequentially sell to the same set of customers and found that firms sell customer data if the customers are naive (i.e., do not anticipate the sale of their information). Our study, however, focuses on the case where two firms simultaneously compete for the same consumers.

There are several other studies that examine the horizontal sharing of individuallevel consumer data in competitive settings. Pagano and Jappelli [30] examined the credit market competition where two differentiated lenders (located in different towns) serve both local borrowers and moving borrowers, who can borrow from both lenders. Their study shows that information sharing benefits lenders by allowing them to better price-discriminate between local borrowers and moving borrowers in the future period, and hence softens the competition in the current period. Chen et al. [9] examined the situation where two firms sell differentiated products to both loyal customers and comparison shoppers. Firms cannot perfectly distinguish between comparison shoppers and the loyal customers. Chen et al.'s results show that information sharing helps firms improve the targetability and avoid overaggressively competing for each other's loyal customers. In a two-period setting, Liu and Serfes [24] studied how the exchange of information softens competition between differentiated firms. Their analysis shows that information sharing not only makes firms less aggressive in acquiring market shares in the first period but also helps firms better price the product according to the customer preferences in the 
second period. The above studies examine the sharing of individual consumer data under the premise that consumers have heterogeneous brand preferences. Our research differentiates from these studies by investigating the sharing of individual consumer data between competing firms when consumers have no brand preference. In addition, the above studies focus on price competition, whereas our study examines the advertising competition between firms.

This paper also contributes to the literature on common-value auctions (CVA) with asymmetrically informed bidders. A CVA is an auction in which the bidders share the correlated but unknown values regarding the auctioned item. It is in contrast to the private-value auction, in which the bidders have independent private valuations of the auctioned item. In this paper, a consumer is of the same value to both firms upon being acquired but the firms are not equally informed about the consumer value. The firm competition can be considered as a CVA with asymmetrically informed bidders. While there is a large body of literature on auctions, CVAs with asymmetrically informed bidders have received less attention in the theoretical work on auctions. EngelbrechtWiggans et al. [12] and Milgrom and Weber [29] study CVAs in which only one bidder has private information (i.e., informed bidder) and show that in equilibrium the informed bidder in general makes a positive expected profit while other bidders make a zero profit. Banerjee [3] and Hausch [18] find that the less-informed bidder with private information may earn a positive expected profit. These studies focus on the common-value winner-pay auctions. Our paper shows that in a common-value all-pay auction, the less-informed firm with private information may make a positive profit.

The literature on CVAs has mixed findings on the value of information. Milgrom and Weber [29] show that by releasing the better-informed bidder's information, the seller can increase its expected revenue. This is because information disclosure, which decreases information asymmetry, between bidders leads firms to compete more aggressively, and hence increases the expected revenue for the seller. Hausch [18] used a special case to illustrate that the seller's expected revenue may be lower if the less-informed bidder receives better information. Banerjee [3] found that a change in the degree of asymmetry between bidders has an ambiguous effect on revenue. These papers focus on winner-pay auctions with conditional commitment of resources, that is, the winner pays the bid only when it wins the auction [1]. The advertising competition in our paper exhibits the feature of unconditional commitment - a firm incurs advertising costs regardless of winning. Therefore, our model can be characterized as a commonvalue all-pay auction. Our analysis shows that the value of information sharing depends on the level of information asymmetry between firms - information sharing increases the total profit of firms (i.e., information sharing is valuable) when the level of information asymmetry between firms is high but reduces the total profit when the level of information asymmetry is low.

All-pay auctions have been used to model a variety of economic and social activities, such as rent seeking and lobbying, patent competition, contests and tournaments, and advertising and promotional competition [1,32]. All-pay auctions with asymmetric bidders, while often observed, are underexplored. To the best of our knowledge, this is the first paper that examines the competitive strategies and information-sharing decisions in a common-value all-pay auction with asymmetrically privately informed bidders.

\section{Model}

We consider two homogeneous firms advertising and selling to a group of consumers. From a firm's perspective, a consumer can be either valuable or nonvaluable. We use T to denote the 
consumer's type and let $\mathrm{T}=\mathrm{H}(\mathrm{T}=\mathrm{L})$ for a valuable (nonvaluable) consumer. A valuable consumer has a high consumption level and generates a positive revenue income to the firm during his or her lifetime relationship with the firm. A nonvaluable consumer, in contrast, has a low consumption level and cannot generate any revenue income to the firm in expectation. For example, BestBuy reported that bargain hunters bring hassle to the retailer by returning products and then buying them back at returned-merchandiser discounts, or by presenting price quotes from Web sites and demanding price matching to its lowest-price pledge [26]. Firms are not willing to serve such consumers because their spending is too low to cover the firms' costs of serving them. We use $\mathrm{V}$ to represent the value of a consumer and let $\mathrm{V}=\mathrm{v}$ for a valuable consumer and $\mathrm{V}=0$ for a nonvaluable consumer. We assume that a positive proportion of the consumers are valuable. Firms cannot directly observe whether a specific customer is valuable or nonvaluable. This is equivalent to the case where firms compete for a representative consumer and this consumer is valuable (nonvaluable) with a positive prior probability, $\mathrm{p}_{\mathrm{H}}=\mathrm{a}\left(\mathrm{p}_{\mathrm{L}}=1-\right.$ $\mathrm{p}_{\mathrm{H}}$. In the subsequent analysis, without loss of generality, we focus on the case with a representative consumer.

Firms use advertising to improve brand awareness and create demand. With individuallevel consumer data, firms can tailor ads to the representative consumer in content and intensity, that is, behavioral targeting. Since this paper focuses on the consumer's ex ante interest in the product rather than the brand, we consider the case where firms tailor the intensity of ads (i.e., the amount of advertising spending) in targeting the consumer. The consumer eventually patronizes the firm that sends more ads to him or her. We use $x_{i}, i \in\{1,2\}$ to denote firm i's advertising spending on the consumer.

onsumer. Even though firms cannot directly observe whether a specific consumer is valuable or nonvaluable, they often receive signals on the value of the consumer. For example, each firm may collect consumer profile and transaction data from its sales channels or acquire the data from marketing intelligence companies. In most practical situations, the firms have different information about the consumer. Without loss of generality, we assume that firm 1 has more information on the same set of consumers than firm 2. For example, when firm 1 sells its products via multiple channels and firm 2 sells only through a single channel, firm 1 is able to collect more data about a consumer via different channels. As a result, firm 1 has more detailed and richer data about the consumer. Based on this data, firm 1 can more thoroughly analyze the consumer and more accurately estimate the consumer's value than firm 2 . It is worth noting that our model can also capture the case where firm 1 has data on more consumers than firm 2 . In this case, we can consider that only firm 1 is informed about the value of a specific consumer and firm 2 is completely uninformed. This is actually a special case of our model.

We model the firms' information as follows. Firm 1 draws a private signal $\mathrm{S}$ from its data about the value of this consumer. This can be considered a case in which firm 1 analyzes its data and generates sales leads from the data. We assume that if a sales lead is generated from a consumer, this consumer can be either a valuable consumer or a nonvaluable consumer. If there is no sales lead from a consumer, the firm can conclude that he or she is a nonvaluable consumer. For example, if the data show that a consumer has made a few purchases over the past three months, this signals that this consumer could potentially be a valuable consumer. However, it is still possible that this consumer may not be valuable. If the data show that the consumer has been inactive for a long period of time, this consumer is considered as a nonvaluable consumer. Mathematically, we assume that $\mathrm{S}$ can be either high (h) or low (1). Firm 1 always draws a high signal from a valuable consumer and draws a high signal from a nonvaluable consumer with 
probability $\zeta^{1}{ }^{1}$ We use ps|T to represent the probability that firm 1 draws a signal $S \in\{h, 1\}$ from a consumer with type $T \in\{H, L\}$ and let

$$
p_{h \mid H}=1, p_{l \mid H}=0, p_{h \mid L}=\zeta, p_{l \mid L}=1-\zeta .
$$

We use $\mathrm{p}_{\mathrm{s}}$ to denote the probability that firm 1 draws a signal $\mathrm{S} \in\{\mathrm{h}, 1\}$ and

$$
p_{S}=p_{S \mid H} p_{H}+p_{S \mid L} p_{L}
$$

The posterior probabilities of the consumer's type $T \in\{\mathrm{H}, \mathrm{L}\}$ after firm 1 receives a signal $S$ $\in\{h, 1\}$ are given by

$$
p_{T \mid S}=\frac{p_{S \mid T} p_{T}}{p_{S}}
$$

To evaluate the informativeness of firm 1's signals, we compare the posterior probabilities $\mathrm{p}_{\mathrm{T} / \mathrm{S}}$ with the prior probabilities $\mathrm{p}_{\mathrm{T}}$ and have

$$
\begin{gathered}
p_{H \mid h}=\frac{\alpha}{\alpha+(1-\alpha) \zeta}>\alpha=p_{H} \\
p_{L \mid l}=1>1-\alpha=p_{L} .
\end{gathered}
$$

Inequality (1) indicates that when firm 1 receives a high signal, $S=h$, firm 1 is more confident that the consumer is a valuable consumer. Inequality (2) indicates that when firm 1 receives a low signal, $\mathrm{S}=1$, firm 1 is more confident that the consumer is a nonvaluable consumer. Firm 1's consumer data is therefore informative.

We use $E[\mathrm{~V} \mid \mathrm{S}]$ to represent the expected value of the consumer for firm 1 given a signal $\mathrm{S} \in\{\mathrm{h}, \mathrm{l}\}$, and

$$
\begin{gathered}
E[V \mid h]=p_{H \mid h} v+p_{L \mid h} \cdot 0=\frac{\alpha}{\alpha+(1-\alpha) \zeta} v, \\
E[V \mid l]=p_{H \mid l} v+p_{L \mid l} 0=0 .
\end{gathered}
$$


It is assumed that firm 2 cannot observe firm 1's signal $S$. Firm 2 draws from its data a different signal $\tilde{S}$. The value of $\tilde{S}_{\text {can be either high }}(\tilde{h})$ or low $(\tilde{l}) . \tilde{S}_{\text {is correlated with } S \text { but is }}$ less accurate than $S$ (as shown below). The signals are likely to be correlated because firms target the same consumer. ${ }^{2}$ Let $\mathrm{p}_{\mathrm{S} \mid \mathrm{S}}$ denote the probabilities of receiving $\tilde{S}_{\in}\{\tilde{h}, \tilde{l}\}$ conditional on $\mathrm{S} \in$ $\{\mathrm{h}, \mathrm{l}\}$. The probabilities $\mathrm{p}_{\mathrm{s} \mid \mathrm{s}}$ are defined as follows:

$$
p_{\tilde{h} \mid h}=p_{\tilde{l} \mid l}=\frac{1+\tau}{2}, p_{\tilde{l} \mid h}=p_{\tilde{h} \mid l}=\frac{1-\tau}{2} .
$$

where $t \in[0,1]$ captures the similarity level of $\tilde{S}$ relative to $S$. When $\tau=1$, the two firms have the same signals about the consumer and, therefore, there is no information asymmetry between them. When $\tau<1$, firm 2's signal is less informative than firm 1's signal (as illustrated below) and there is information asymmetry between firms. In particular, when $\tau=0$, the signal $\tilde{S}_{\text {does }}$ not provide any additional information to firm 2 because given an S, firm 2 draws $\tilde{S}=\tilde{h}$ or $\tilde{S}=$ $\tilde{l}$ with equal probability (0.5). As $\tau$ increases, $\tilde{S}$ conveys more similar information as $S$ and information asymmetry between the firms decreases. We assume that $\tau$ is common knowledge. Even though a firm cannot observe the signals of its competitor, it is aware of the richness of the data that the competitor possesses. For example, a firm is often aware of the variety of channels from which the other firm serves its consumers and thus acquires consumer data. In this regard, even if the firm cannot directly observe its competitor's consumer data, it can infer to what extent its competitor's consumer data is rich for analysis.

Based on Equation (3), we derive the probabilities for firm 2 receiving a signal $\tilde{S} \in\{\tilde{h}, \tilde{l}\}:$

$$
\rho_{\tilde{S}}=p_{\tilde{S} \mid h}+p_{\tilde{s} \mid l} p_{l}
$$

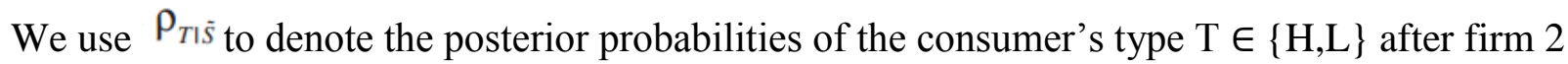
draws a signal $\tilde{S} \in\{\tilde{h}, \tilde{l}\}$ Using Bayes's rule, we get

$$
\rho_{H \mid \tilde{h}}=\frac{\left(p_{\tilde{h} \mid h} p_{h \mid H}+p_{\tilde{h} \mid l} p_{l \mid H}\right) p_{H}}{p_{\tilde{h} \mid h} p_{h}+p_{\tilde{h} \mid l} p_{l}}, \rho_{L \mid \tilde{l}}=\frac{\left(p_{\tilde{l} \mid h} p_{h \mid L}+p_{\tilde{l} \mid l} p_{l \mid L}\right) p_{L}}{p_{\tilde{l} \mid h} p_{h}+p_{\tilde{l} \mid l} p_{l}} .
$$

To evaluate the informativeness of firm 2's signals, we compare the posterior probabilities $\rho_{T \mid \tilde{S}}$ with the prior probabilities $\mathrm{p}_{\mathrm{T}}$ and have 


$$
\begin{gathered}
\rho_{H \mid \tilde{h}}>p_{H}=\alpha \\
\rho_{L \mid \tilde{l}}>p_{L}=1-\alpha .
\end{gathered}
$$

Inequality (6) shows that when both firms receive high signals (firm 1 receives $\mathrm{S}=\mathrm{h}$ and firm 2 receives $\tilde{S}=h$ ), firm 1 is more confident that the consumer is a valuable consumer than firm 2. Inequality (7) shows that when both firms receive low signals (firm 1 receives $S=1$ and firm 2 receives $\tilde{S}=\tilde{l}$ ), firm 1 is more confident than is firm 2 that the consumer is a nonvaluable consumer. Therefore, firm 1's signal is more accurate (or more informative) than firm 2's, and firm 1 is better informed than firm 2 . Given the signal $\tilde{S}$, the expected value of the consumer to firm 2 is

$$
E[V \mid \tilde{S}]=\rho_{h \mid \tilde{S}} E[V \mid h]+\rho_{l \mid \tilde{S}} E[V \mid l],
$$

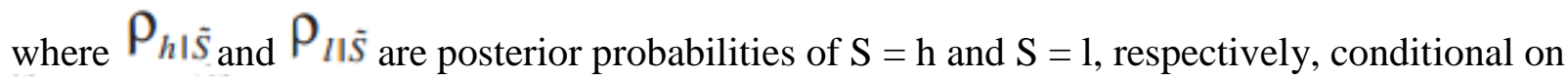
$\tilde{S} \in\{\tilde{h}, \tilde{l}\}$. Using Bayes's rule, we get

$$
\rho_{S \mid \tilde{S}}=\frac{p_{S \mid \tilde{S}} p_{S}}{\rho_{\tilde{S}}}, S \in\{h, l\}, \tilde{S} \in\{\tilde{h}, \tilde{l}\} .
$$

Then we can show the following relationship among the expected values:

Lemma 1: $E[V \mid l] \leq E[V \mid \tilde{l}] \leq E[V] \leq E[V \mid \tilde{h}] \leq E[V \mid h]$.

Lemma 1 suggests that a higher signal $\tilde{S}=\tilde{h}$ is less likely to indicate a valuable consumer than $\mathrm{S}=\mathrm{h}$. Similarly, a low signal $\tilde{S}=\tilde{l}$ is less likely to indicate a nonvaluable consumer than $\mathrm{S}$ $=1$. This further confirms that the signal $\tilde{S}$ provides less accurate information than the signal S. All the proofs are in the Appendix.

The sequence of events in our model is as follows. First, firm 1 (the better-informed firm) decides whether and how to share consumer data with firm 2. Second, both firms draw their private signals about the consumer from their consumer data (i.e., firm 1 observes $\mathrm{S}$ and firm 2 observes $\tilde{S})$. Third, both firms simultaneously determine their advertising spending, $\mathrm{x}_{\mathrm{i}}(\mathrm{i}=1,2)$, in targeting the consumer. Fourth, the firm that spends more in advertising wins the consumer and gains a revenue $\mathrm{V}$ from this consumer. Figure 1 illustrates the timing of events. Both the firms and the consumer are risk-neutral. We assume that everything is common knowledge except the consumer's value $\mathrm{V}$ and the two private signals $\mathrm{S}$ and $\tilde{S}$. We use backward induction to solve the game. The next section investigates the firms' competitive strategies in target 
advertising. The Sharing Consumer Data section examines the firms' consumer data-sharing decisions, given the subgame equilibrium characterized in the next section.

\section{Firm Competition}

This section examines the Bayesian equilibrium of the firm advertising competition. Since the consumer's true value is the same for both firms and target advertising is costly for firms, the firm competition has the same features of a common-value allpay auction. We thus use a common-value all-pay auction framework to analyze the competition game. In the competition, firm $i(i=1,2)$ chooses its advertising spending, $\mathrm{x}_{\mathrm{i}}$, to maximize its expected profit from the consumer, $\pi_{i}$. We find that there exists no pure-strategy equilibrium for the firm competition. The rationale is that if firm 2 spends a deterministic amount $\mathrm{x}_{2}$ in advertising, firm 1's best response is always to spend more than $\mathrm{x}_{2}$ as long as $\mathrm{E}[\mathrm{V} \mid \mathrm{S}]>\mathrm{x}_{2}$. As a result, firm 2 wins the consumer only when $E[V \mid S] \leq x_{2}$, which yields a nonpositive expected profit for firm 2 . This is a typical case of the winner's curse. Therefore, firm 2 must use a randomized strategy in the equilibrium. In marketing, mixed strategies can be interpreted as the frequent dispersion of firms' sales offers or promotions.

Let $\mathrm{F}_{1}(x \mid \mathrm{S})=\operatorname{Pr}\left(\mathrm{x}_{1} \leq x \mid \mathrm{S}\right)$ denote firm 1's mixed strategy in equilibrium, where $\mathrm{F}_{1}(x \mid \mathrm{S})$ is the cumulative distribution function (CDF) of firm 1's randomized advertising spending conditional on the signal $S$. Similarly, let $F_{2}(x \mid \tilde{S})=\operatorname{Pr}\left(x_{2} \leq x \mid \tilde{S}\right)$ ) denote firm 2's mixed strategy in equilibrium, where ${ }^{F_{2}(x \mid \tilde{S})}$ is the CDF of firm 2's randomized advertising spending conditional on the signal $\tilde{S}$. Then firm 1's expected profit function can be represented as

$$
\pi_{1}\left(x_{1} \mid S\right)=p_{\tilde{h} \mid S} F_{2}\left(x_{1} \mid \tilde{h}\right) E[V \mid S]+p_{\tilde{l} \mid S} F_{2}\left(x_{1} \mid \tilde{l}\right) E[V \mid S]-x_{1} .
$$

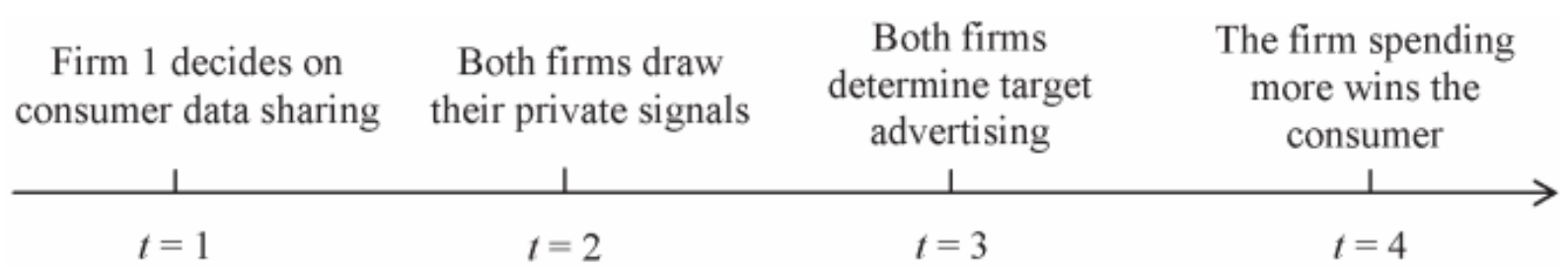

Figure 1. The Timing of Events

The first term on the right-hand side of Equation (10) is firm 1's expected revenue in competition when firm 2 draws $\tilde{S}=\tilde{h}$. The second term is the expected revenue when firm 2 draws $\tilde{S}=\tilde{l}$. And the third term is firm 1's advertising spending. Similarly, firm 2's expected profit function can be represented as

$$
\pi_{2}\left(x_{2} \mid \tilde{S}\right)=\rho_{h \mid \tilde{S}} F_{1}\left(x_{2} \mid h\right) E[V \mid h]+\rho_{l \mid \tilde{S}} F_{1}\left(x_{2} \mid l\right) E[V \mid l]-x_{2} .
$$


The first term on the right-hand side of Equation (11) is firm 2's expected revenue in competition when firm 1 draws $S=h$. The second term is firm 2's expected revenue when firm 1 draws $S=l$. And the third term is firm 2's advertising spending.

Proposition 1 characterizes the firms' equilibrium advertising strategies ${ }^{\left(F_{1}(x \mid S)\right.}$ and $\left.F_{2}(x \mid \tilde{S})\right)$ for the case of $p_{h} \leq p_{l}$, that is, firm 1 is more likely to draw a low signal:

Proposition 1: When $p_{h} \leq p_{l}$, the firms' equilibrium strategies can be characterized as follows:

(a) When $S=l$, firm 1 spends zero in target advertising (i.e., no targeting). When $S=h$, firm 1 spends in target advertising according to

$$
F_{1}(x \mid h)=\frac{x}{\rho_{h \mid \tilde{h}} E[V \mid h]}, x \in[0, E[V \mid \tilde{h}]] .
$$

(b) When $\tilde{S}=\tilde{l}$, firm 2 spends zero in target advertising. When $\tilde{S}=\tilde{h}$, firm 2 spends in target advertising according to

$$
F_{2}(x \mid \tilde{h})=\frac{\left(\rho_{l \mid \tilde{h}}-p_{\tilde{l} \mid h}\right) E[V \mid h]+x}{p_{\tilde{h} \mid h} E[V \mid h]}, x \in[0, E[V \mid \tilde{h}]] .
$$

To help understand Proposition 1, Figure 2a depicts the support of the firms' randomized advertising spending. When $p_{h} \leq p_{l}$, firm 1's advertising strategy can be explained as follows. Firm 1 estimates the consumer value and decides its advertising spending based on its signal $S$. When firm 1 draws $S=l$, it expects that the consumer value is $\mathrm{E}[\mathrm{V} \mid l]=0$. Therefore, firm 1 does not target the consumer at all. When firm 1 draws $S=h$, it expects that the consumer value is $\mathrm{E}[\mathrm{V} \mid h]$. Based on Lemma 1, we have that $\mathrm{E}[\mathrm{V} \mid h]>\max \{E[V \mid \tilde{h}], E[V \mid \tilde{l}]\}$ and firm 2 never spends more than $E[V \mid \tilde{h}]$. Firm 1 randomizes its advertising spending over $[0, E[V \mid \tilde{h}]]$. 


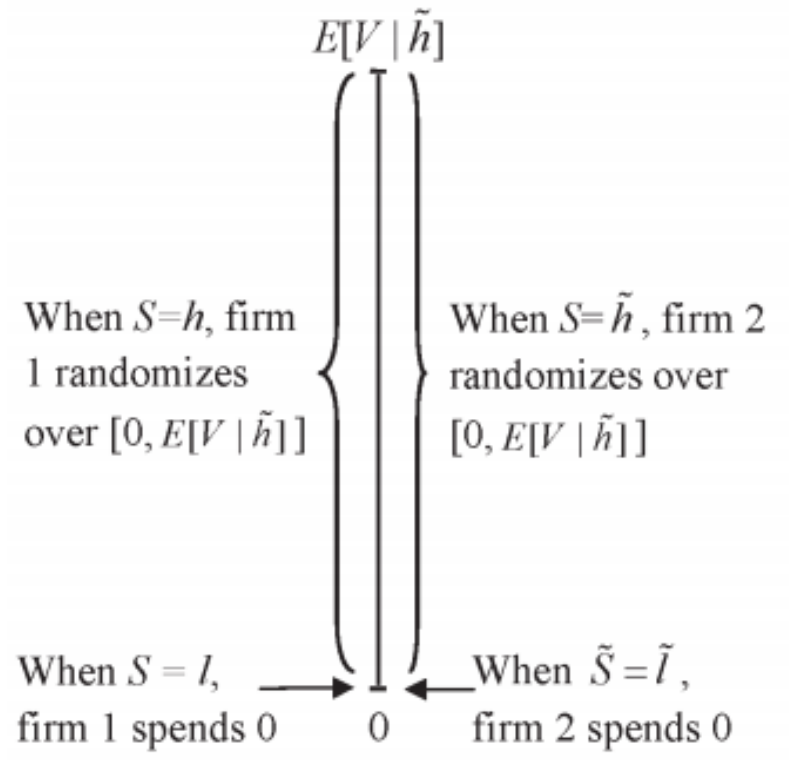

(a) Firm competition when $p_{h} \leq p_{l}$

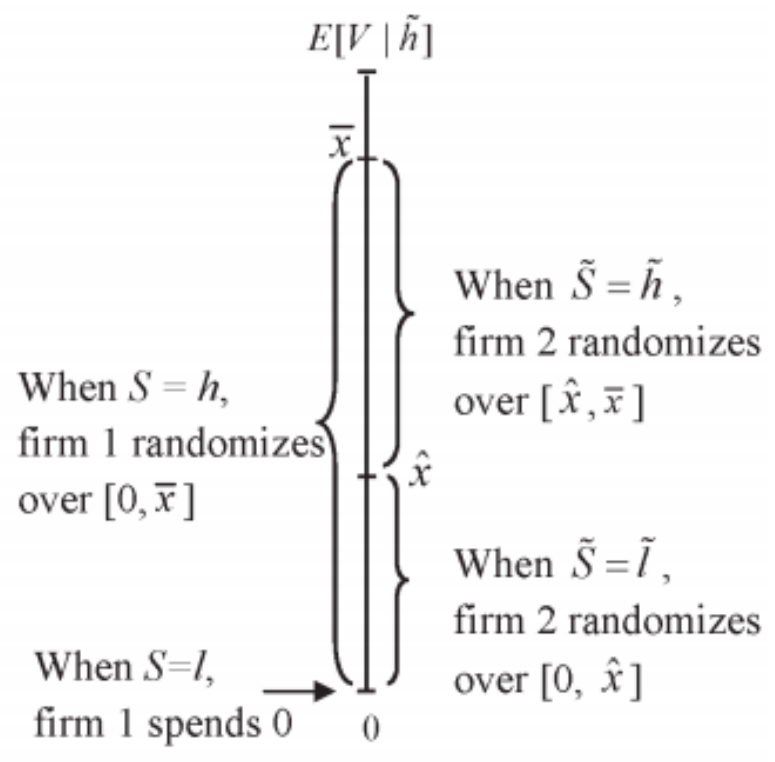

(b) Firm competition when $p_{h}>p_{l}$

\section{Figure 2. The Equilibrium Scenarios of Firm Competition}

Similarly, firm 2 estimates the consumer value and decides its advertising spending based on its signal $\tilde{S}$. When firm 2 draws $\tilde{S}=\tilde{l}$, it expects that the consumer value is $E[V \mid \tilde{l}] \geq 0$ (the equality holds if and only if $\tau=1$ ). However, we find that firm 2 does not spend in advertising either. This is a due to the concern of the winner's curse. When firm 2 draws $\tilde{S}=\tilde{l}$, firm 1 may have either a high signal $S=h$ or a low signal $S=l$. If firm 1 draws $S=l$, it does not target this consumer because $\mathrm{E}[\mathrm{V} \mid l]=0$. In this case, even though firm 2 can win the consumer by spending a positive amount in advertising, firm 2's profit is negative (i.e., the winner's curse). If firm 1 draws $S=h$, firm 1 will advertise aggressively such that firm 2 never earns a positive expected profit in equilibrium. As a result, firm 2 can never do better than not advertising at all. This is why firm 2 spends zero when $\tilde{S}=\tilde{l}$. When firm 2 draws $\tilde{S}=\tilde{h}$, firm 2 randomizes its advertising spending over the support $[0, E[V \mid \tilde{h}]]$.

Proposition 2 characterizes the firms' equilibrium advertising strategies when $\mathrm{p}_{h}>\mathrm{p}_{l}$, that is, firm 1 is more likely to draw a high signal:

Proposition 2: When $p_{h}>p_{l}$, the firms' equilibrium strategies can be characterized as follows:

1. When $S=l$, firm 1 spends zero in target advertising. When $S=h$, firm 1 spends in target advertising according to 


$$
F_{1}(x \mid h)=\left\{\begin{array}{l}
\frac{x}{\rho_{h \mid \tilde{h}} E[V \mid h]}, x \in[0, \hat{x}], \\
\frac{\rho_{h \mid \tilde{h}} E[V \mid h]-\bar{x}+x}{\rho_{h \mid \tilde{h}} E[V \mid h]}, x \in[\hat{x}, \bar{x}] .
\end{array}\right.
$$

2. When $\tilde{S}=\tilde{l}$, firm 2 spends in target advertising according to

$$
F_{2}(x \mid \tilde{l})=\frac{E[V \mid h]-\bar{x}+x}{p_{\tilde{l} \mid h} E[V \mid h]}, x \in[0, \hat{x}] .
$$

When $\tilde{S}=\tilde{h}$, firm 2 spends in target advertising according to

$$
F_{2}(x \mid \tilde{h})=\frac{p_{\tilde{h} \mid h} E[V \mid h]-\bar{x}+x}{p_{\tilde{h} \mid h} E[V \mid h]}, x \in[\hat{x}, \bar{x}] \text {, }
$$

where the cutoff levels $\hat{x}$ and $\bar{x}$ are defined in the Appendix

Figure $2 \mathrm{~b}$ depicts the support of firms' randomized advertising spending when $\mathrm{p}_{h}>\mathrm{p}_{l}$. Similar to the case of $\mathrm{p}_{h} \leq \mathrm{p}_{l}$, firm 1 does not spend in target advertising when it draws a signal $\mathrm{S}$ $=l$. When firm 1 draws $S=h$, firm 1 randomizes its advertising spending but competes less aggressively than in the case of $p_{h} \leq p_{l}$. This is indicated by the finding that the upper bound of firm 1's advertising spending is less than $E[V \mid \tilde{h}]$.

Since firm 1 competes less aggressively, firm 2 no longer finds it optimal to always spend zero when $\tilde{S}=\tilde{l}$. Instead, it becomes opportunistic and would like to spend in targeting the consumer, hoping to win if firm 1 draws $S=h$. As a result, firm 2 randomizes its advertising spending over the support $[0, \hat{x}]$, where $\hat{x}>0$. In other words, firm 1 's less aggressiveness motivates firm 2 to compete more aggressively when firm 2 draws $\tilde{S}=\tilde{l}$. When firm 2 draws $\tilde{S}=\tilde{h}$, it randomizes its advertising spending $\mathrm{x}_{2}$ over $[\hat{x}, \bar{x}]$.

When $\mathrm{p}_{h}>\mathrm{p} l$, firm 1 spends a positive amount in advertising only when it draws $S=h$. Firm 2 spends a positive amount in advertising both when $\tilde{S}=\tilde{h}$ and when $\tilde{S}=\tilde{l}$. Therefore, firm 1 drawing $S=h$ competes with firm 2 both when firm 2 draws $\tilde{S}=\tilde{l}$ when firm 2 draws $\tilde{S}=\tilde{h}$. This leads to a kink point at $\hat{x}$ in firm 1's CDF, $\mathrm{F}_{1}(x \mid h)$. 
When $\tau=0$, firm 2's information provides no additional message and only firm 1 has private information. This is a special case of the equilibria identified above. It is worth noting that when $\tau=1$, the signals $S$ and $\tilde{S}$ are identical, that is, the firms always obtain the same information. The CDFs of the firms' advertising spending are also identical. When they draw low signals, $\mathrm{S}=\tilde{S}=1$, neither firm spends in target advertising on this consumer. When they draw high signals, $\mathrm{S}=\tilde{S}=h$, they spend in target advertising following the same CDF:

$$
F(x \mid h)=\frac{x}{E[V \mid h]}, x \in[0, E[V \mid h]] .
$$

The firms compete head-to-head, and their expected advertising spendings are always the same, that is, $E\left[x_{1} \mid h\right]={ }^{E\left[x_{2} \mid \tilde{h}\right]}$ and $E\left[x_{1}\right]=E\left[x_{2}\right]$. When $\tau<1$, the firms obtain different information and spend following different CDFs as shown in Propositions 1 and 2. Proposition 3 compares the firms' expected advertising spending when information asymmetry between the firms exists, that is, $\tau<1$ :

Proposition 3: When $\tau<1$ :

(a) If $p_{h} \leq p_{l}, O=E\left[x_{1} \mid l\right]=E\left[x_{2} \mid \tilde{l}\right]<E\left[x_{2} \mid \tilde{h}\right] \leq E\left[x_{1} \mid h\right]\left(E\left[x_{2} \mid \tilde{h}\right]=E\left[x_{1} \mid h\right]\right.$ only when $\left.p_{h}=p_{l}\right)$.

(b) If $p_{h}>p_{l}, O=E\left[x_{l} \mid l\right]<E\left[x_{2} \mid \tilde{l}\right]<E\left[x_{1} \mid h\right]<E\left[x_{2} \mid \tilde{h}\right]$.

3. Firms' overall expected advertising spendings on the consumer are always equal, that is, $E\left[x_{1}\right]=E\left[x_{2}\right]$.

When $\mathrm{p}_{\mathrm{h}}<\mathrm{p}_{\mathrm{l}}$, firm 1's expected advertising spending when firm 1 draws $S=h$ is higher than that of firm 2 when firm 2 draws $\tilde{S}=\tilde{h}$, that is, $E\left[x_{1} \mid h\right]>E\left[x_{2} \mid \tilde{h}\right]$. Lemma 1 shows that a signal $S=h$ is a stronger predictor of a valuable consumer than a signal $\tilde{S}=\tilde{h}$. Therefore, firm 1 drawing $S=h$ is more willing to spend in target advertising on the consumer than firm 2 drawing $\tilde{S}=\tilde{h}$. When firms draw low signals $(S=l$ for firm 1 or $\tilde{S}=\tilde{l}$ for firm 2 ), they do not spend in target advertising, as shown in Proposition 1.

When $\mathrm{p}_{h}>\mathrm{p}_{l}$, firm 1's expected advertising spending when $S=h$ is less than firm 2's expected advertising spending when $\tilde{S}=\tilde{h}$, that is, $E\left[x_{1} \mid h\right]<E\left[x_{2} \mid \tilde{h}\right]$. This also evidences that firm 1 competes less aggressively when $\mathrm{p}_{h}>\mathrm{p}_{l}$. Instead of pursuing higher winning probabilities, firm 1 chooses to save the advertising spending and bets on the chance that firm 2 draws a low signal $S=l$. Because firm 1 competes less aggressively, firm 2 no longer finds it optimal to give up the competition when it draws a low signal $\tilde{S}=\tilde{l}$. Instead, firm $\} 2$ would like to spend a positive amount in target advertising when $\tilde{S}=\tilde{l}$, hoping to beat firm 1 when firm 1 draws $S=h$. Nevertheless, firm 1 with $S=h$ still advertises more aggressively than firm 2 with $\tilde{S}=\tilde{l}$, that is, 
$E\left[x_{1} \mid h\right]>E\left[x_{2} \mid \tilde{l}\right]$. Again, firm 1 does not spend in target advertising when it draws $S=l$. As a result, $E\left[x_{2} \mid \bar{l}\right]>E\left[x_{1} \mid l\right]=0$.

Proposition 3 also presents an interesting finding-firms' overall expected advertising spendings are always the same, despite their information difference. This result reveals an important role of information in the target advertising competition. In other words, better information does not help a firm save the cost of advertising in competition. Instead, better information enables the firm to focus its advertising spending on the more valuable consumers. The firm can use consumer information to better allocate its marketing resources and improve the effectiveness of its target advertising. Proposition 4 summarizes the expected profits of firms in competition:

Proposition 4: (a) When firms have symmetric information about the consumer, that is, $\tau=1$, neither firm makes a positive profit. (b) When firms have asymmetric information, that is, $\tau<1$, firm 1's expected profit is always positive. Firm 2's expected profit is positive when $\mathrm{p}_{h}>\mathrm{p}_{l}$ and $\tau>0$. Firm 1's expected profit is always higher than firm 2's expected profit.

Proposition 4 confirms the value of individual-level consumer data in target advertising. When $\tau=1$, firms have the same information and hence always engage in the head-to-head competition. Neither firm makes a positive expected profit in this case.

When $\tau<1$, firm 1 has better consumer information than firm 2 . The better-informed firm always makes a higher expected profit than the less-informed firm. The expected profit of firm 2 depends on the distribution of the firms' signals. When $\mathrm{p}_{\mathrm{h}} \leq \mathrm{p}_{\mathrm{l}}$, firm 2 does not make a positive expected profit. This result is consistent with the findings in the existing literature on common-value auctions with asymmetrically informed bidders $[12,19,29]$. When $\mathrm{p}_{\mathrm{h}}>\mathrm{p}_{\mathrm{l}}$, however, firm 2 also makes a positive expected profit when it draws an informative signal (i.e., $\tau>0$ ). This is because firm 2's signal, even though less accurate, is still private information. Firm 1 does not directly observe firm 2's signal. Propositions 2 and 3 show that firms compete less aggressively when $\mathrm{p}_{\mathrm{h}}>\mathrm{p}_{\mathrm{l}}$. In this case, firm 2 's private signal enables firm 2 to reap an information rent in the advertising competition.

It is worth remarking that this finding contributes to the literature on common-value auctions with asymmetrically informed bidders. Although some prior studies have identified that the less-informed bidder with private information may earn a positive expected profit (e.g., [3, 18]), the finding was derived in the setting of winner-pay auctions. Our model on the costly advertising competition suggests that the less-informed bidder with private information may still earn a positive expected profit in the setting of all-pay auctions. In addition, the existing literature $[3,12,18,29]$ has separately examined the case where only the better-informed bidder earns a positive expected profit and the case where both the better-informed bidder and the lessinformed bidder earn positive profits. This study, in contrast, uses a more generalized model to illustrate both cases.

\section{Sharing Consumer Data}


The preceding section characterized the advertising competition when firms have asymmetric information about the consumer value. In this section, we examine how the change in information asymmetry influences the firm competition. This analysis helps answer the key research question, that is, whether the better-informed firm (firm 1) has an incentive to share its consumer data with the less-informed firm (firm 2).

When firm 1 shares more consumer data with firm 2, the two firms have more similar data about the consumer. We use $t \in[0,1]$ to measure the similarity level between the firms' signals $S$ and $\tilde{S}$. When $\tau$ is larger (smaller), the two signals are more (less) similar, or the level of information asymmetry is lower (higher). Therefore, $\tau$ can also be used to represent the degree of consumer data sharing.

Following the existing literature (e.g., [9]), we consider two possible ways for firm 1 to share its consumer data. 3 Firm 1 can either give its consumer data to firm 2 for free (i.e., voluntary sharing) or sell its consumer data to firm 2 (i.e., paid sharing). The specific mechanism of data sharing or trading is not the focus of this study. Instead, we examine the feasibility of data sharing to shed light on the viability of consumer data exchange. The consumer data exchange is viable only when firms have incentives to share or trade consumer data. According to Chen et al. [9], we examine the following two sets of conditions:

1. The conditions for voluntary sharing: $\partial \pi_{1} / \partial \tau>0$ and $\partial \pi_{2} / \partial \tau \geq 0$. That is, firm 1 is willing to give data to firm 2 for free as long as it can make a higher profit by reducing information asymmetry. The level of information asymmetry is reduced only if firm 2 accepts and uses firm 1's consumer data in target advertising. Therefore voluntary sharing happens only if firm 2 is at least not worse off with a reduced level of information asymmetry;

2. The conditions for paid sharing: $\partial \pi_{1} / \partial \tau+\partial \pi_{2} / \partial \tau>0$ and $\partial \pi_{2} / \partial \tau>0$. That is, firm 1 is willing to sell its consumer data to firm 2 only if the monetary compensation of the transaction is higher than its loss. This requires that the total profit of the two firms is higher with reduced information asymmetry. Also, firm 2 is willing to buy consumer data from firm 1 only if it is at least better off after the transaction.

To help understand the effect of information asymmetry on the firm competition, we first examine how the change of $t$ influences the firms' spending in target advertising:

Proposition 5: (a) When $p_{h} \leq p_{l}$, both firms' expected spendings (E[x $]$ and $\left.E\left[x_{2}\right]\right)$ are increasing in $\tau \in[0,1]$. Moreover,

(i) $\quad E\left[x_{1} \mid h\right]$ is increasing in $\tau$ for $\tau \in[0,1]$;

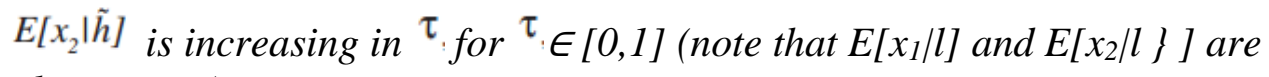
always zero). 
(b) When $p_{h}>p_{l}$, both firms' expected spendings $\left(E\left[x_{1}\right]\right.$ and $\left.E\left[x_{2}\right]\right)$ are decreasing in $t$ for $\tau_{. .} \in\left[0, \tau_{.1}\right]$ and increasing in $\tau_{\text {for } t} \in\left(\tau_{-1}, 1\right]$. Moreover, $E\left[x_{1} \mid h\right]$ is decreasing in $\tau_{\text {. }}$ for $\tau_{.} \in\left[0, \tau_{.1}\right]$ and increasing in $\tau_{. f o r} \tau_{\ldots} \in\left(\tau_{.1}, 1\right]$ :

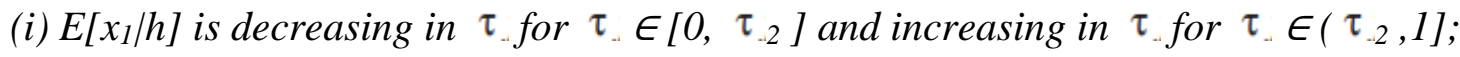

$$
\begin{aligned}
& E\left[x _ { 2 } [ \tilde { l } ] \text { is always decreasing in } { } ^ { \tau } \text { for } { } ^ { \tau } \in [ 0 , 1 ] \left(E\left[x_{1} \mid l\right] \text { is always zero); where }{ }^{\tau} 1\right.\right. \\
& <{ }^{\tau} 2 .{ }^{\tau} 1 \text { and }{ }^{\tau} 2 \text { are defined in the Appendix. }
\end{aligned}
$$

A firm's competitive aggressiveness can be represented by its expected advertising spending. Proposition 5 indicates that reducing information asymmetry has mixed effects on the firms' overall competitive aggressiveness. When t increases, firm 2's signal is getting closer to firm 1's and information asymmetry decreases. When firm 2 draws $\tilde{S}=\tilde{h}$, it is more likely that firm 1 draws $S=h$. Therefore, firm 2 is more confident that the consumer is a valuable consumer. Firm 2 is thus more willing to advertise. Similarly, when firm 2 draws $\tilde{S}=\hat{l}$, it is also more likely that firm 1 draws $S=l$. Therefore, firm 2 is more confident that the consumer is a nonvaluable consumer. Firm 2 is thus less willing to advertise. Firm 2's overall competitive aggressiveness is determined by the trade-off between these two countervailing effects.

When $\mathrm{p}_{h} \leq \mathrm{p}_{l}$, the first effect always dominates the second effect. As a result, the decrease in information asymmetry drives firm 2 to be more aggressive and intensifies the firm competition. Both firms' overall expected advertising spendings are increasing in $\tau$. Also, their expected advertising spendings conditional on the high signals are increasing in $\tau$. Figure $3 \mathrm{a}$ illustrates the firms' expected advertising spendings when $\mathrm{p}_{h} \leq \mathrm{p}_{l}$. We let $E[V \mid h]=10$ and $\mathrm{p}_{h}=$ 0.3 .

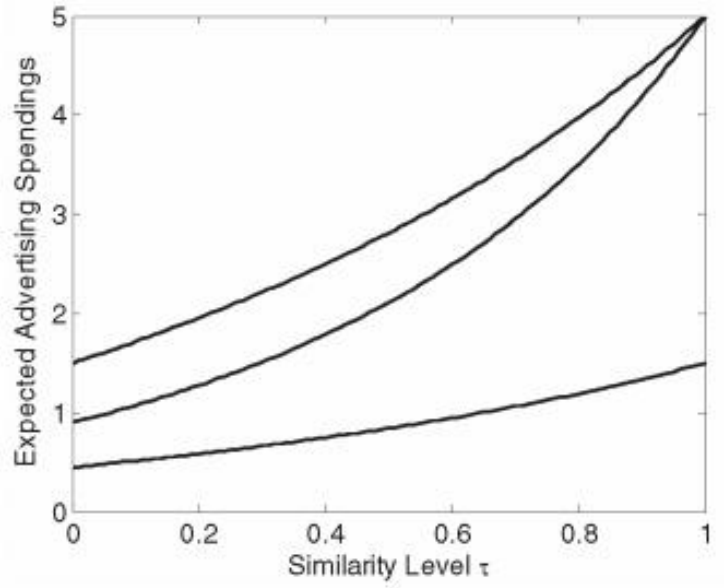

(a) $p_{h} \leq p_{t}$

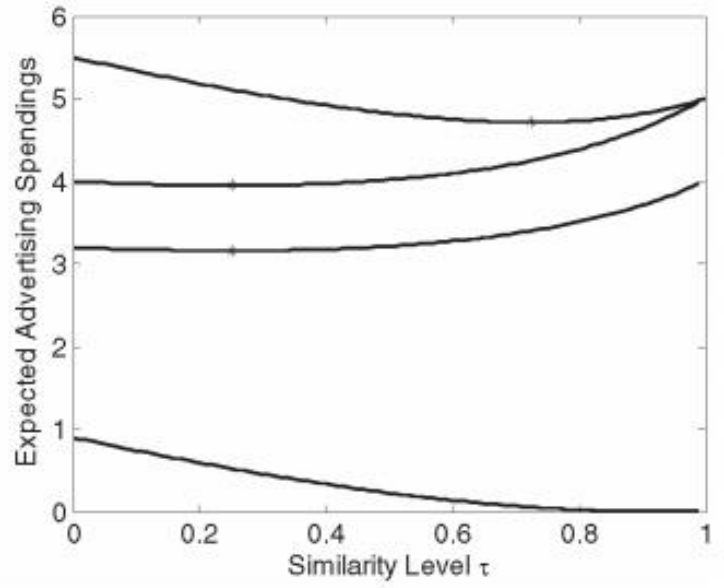

(b) $p_{h}>p_{l}$

Figure 3. Firms' Expected Advertising Spendings

When $\mathrm{p}_{h}>\mathrm{p}_{l}$, the first effect dominates the second effect when $J$ is large but is dominated by the second effect when $\tau$ is small. Therefore, firms may compete less aggressively when information asymmetry decreases. Proposition 5 shows that firms' overall expected 
advertising spendings are first decreasing in $\tau$ when $\tau \in\left[0, \tau_{1}\right]$ and then increasing in $\tau$ when $\tau_{\in(} \tau_{1,1]}$. The firms compete the least aggressively when $\tau=\tau_{1}$. This indicates that the firm competition is first softened and then intensified when information asymmetry decreases. Figure $3 \mathrm{~b}$ illustrates firms' expected advertising spendings when $\mathrm{p}_{\mathrm{h}}>\mathrm{p}_{l}$. Let $E[V \mid h]=$ 10 and $\mathrm{p}_{h}=0.8$. We have $\tau_{1=0.2525 \text { and }} \tau_{2=0.7239}$.

The firms' expected advertising spendings conditional on signals provide more insights on the firms' competitive aggressiveness. When $\tau$ increases, firm 2 drawing $\tilde{S}=\tilde{l}$ is more confident that the consumer is a nonvaluable consumer. Firm 2 is thus less willing to spend in advertising. Its conditional expected spending $E\left[x_{2} \mid \tilde{l}\right]$ is always decreasing in $\tau$. Firm 2's less aggressiveness when $\tilde{S}=\tilde{l}$ also dampens firm 1's incentive to compete. This explains why firm 1 's expected spending conditional on $S=h$, that is, $E\left[x_{1} \mid h\right]$, is decreasing in $\tau_{\text {when }} \tau \in\left[0, \tau_{1}\right.$ ]. But when firm 2 draws $S\}=h$ \}, it is more confident that the consumer is a valuable consumer. Firm 2 is thus more willing to advertise. Firm 2's more aggressiveness when $\tilde{S}=\tilde{h}$ motivates firm 1 to spend more in advertising. This explains why $E[\mathrm{x} 1 \mid \mathrm{h}]$ is increasing in $\mathrm{t}$ when $\tau_{\in(} \tau_{1}$ , 1]. Firm 1's expected advertising spending when $S=h$ is the lowest when $\tau=\tau_{1}$.

In equilibrium, firm 1's competitive aggressiveness also influences firm 2's advertising strategies when firm 2 draws $\tilde{S}=\tilde{h}$. That is why firm 2's expected spending, $E\left[x_{2} \mid \tilde{h}\right]$, changes in a similar way as firm 1's expected advertising spending, $E\left[x_{1} \mid h\right]$. In particular, firm 2's expected advertising spending when $\tilde{S}=\tilde{h}$. is first decreasing in $\tau$ when $\tau \in\left[0, \tau_{2}\right]$ and then increasing in $\mathrm{t}$ when $\tau \in\left(\tau_{2}, 1\right]$. Firm 2 advertises the least aggressively when $t=t 2$. It is

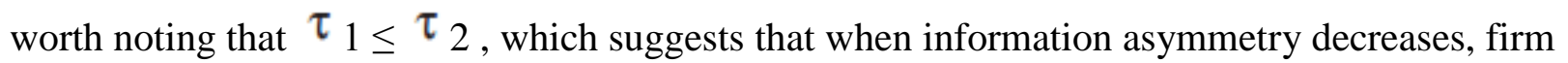
1 first becomes more aggressive in advertising spending before firm 2 does. This is because firm 1 does not want firm 2's improved information to undermine its competitive advantage. Firm 1's better information makes it more confident than firm 2 in increasing spending on target advertising. Proposition 6 illustrates the effects of information asymmetry on the firms' expected profits:

Proposition 6: (a) Firm 1's expected profit is always decreasing in $\tau$ for $\tau \in[0,1]$. (b) When $p_{h} \leq p_{l}$, firm 2 's expected profit is always zero. When $p_{h}>p_{l}$, firm 2 's expected profit is increasing in $\left.\tau_{\text {for }} \tau_{\in[0,} \tau_{3}\right]$, and decreasing in $\tau_{\text {for }} \tau_{\in} \tau_{3,1]}\left(\tau_{3}\right.$ is defined in the Appendix).

When $\mathrm{p}_{h} \leq \mathrm{p}_{l}$, as Proposition 5a shows, the decrease in information asymmetry always intensifies the firm competition. Therefore, firm 1's expected profit is always decreasing in $\tau$ (firm 2's expected profit is always zero). Figure 4a illustrates the firms' expected profits when $\mathrm{p}_{h}$ $\leq \mathrm{p}_{l}$. We let $\mathrm{E}[\mathrm{V} \mid h]=10$ and $\mathrm{p}_{h}=0.3$.

When $\mathrm{p}_{h}>\mathrm{p}_{l}$, as Proposition 5b shows, the decrease in information asymmetry softens the firm competition when the level of information asymmetry is high. One might expect that this is a win-win situation and that both firms benefit from the softened competition. However, as Proposition 6a shows, firm 1 does not directly benefit from the softened competition. Its 
expected profit is always decreasing in $\tau$. This is because when firm 1 advertises less, it is also less likely to win the consumer. Figure $4 \mathrm{~b}$ illustrates the firms' expected profits when $\mathrm{p}_{h}>\mathrm{p}_{l}$. We let $\mathrm{E}[\mathrm{V} \mid h]=10$ and $\mathrm{p}_{h}=0.8$. We have $\tau_{3}=0.6126$.

In contrast, firm 2 may directly benefit from the softened competition when the level of information asymmetry is high (i.e., $\tau$ is small). When $\mathrm{t}$ is small, firms compete less aggressively as information asymmetry decreases. Firm 1's less aggressiveness in competition not only helps firm 2 save advertising spending but also enables firm 2 to win the consumer with a higher probability. As a result, firm 2 directly benefits from the softened competition and obtains a higher expected profit. When $t$ is large, the decrease in information asymmetry drives the firms to spend more in advertising. Such intensified competition hurts both firms. Therefore, firm 2's expected profit is increasing in $\tau$ when $\tau \in\left[\begin{array}{ll}0, & \tau_{3}\end{array}\right]$ and decreasing in $\tau$ when $\tau \in($ $\left.\tau{ }_{3}, 1\right]$. Its expected profit is the highest when $\tau=\tau$.

Proposition 6a suggests that $\partial \pi_{1} / \partial \tau>0$ never holds. Therefore, firm 1 does not directly benefit from the softened competition in target advertising and therefore never voluntarily gives its consumer data to firm 2 for free. This finding is in contrast to the finding in the existing literature. For example, Chen et al. [9] show that a better-informed firm may find it profitable to voluntarily give away its consumer data to its competitor when the firms' targetability is low. However, our analysis suggests that such voluntary sharing of consumer information is unlikely to occur in a more competitive setting, although information sharing may soften the competition. The competition examined in our setting is more competitive than that in Chen et al. [9] for two reasons. First, in Chen et al., some consumers still have brand preferences. In contrast, we examine the case where the two firms compete head-to-head for the consumer who has no brand preference at all. Second, Chen et al. consider a price competition, which is equivalent to a winner-pay auction (i.e., the loser does not incur any cost). In contrast, we consider an advertising competition, which is equivalent to an all-pay auction (i.e., the loser also incurs the advertising cost). As a result, the advertising competition is more costly and the better-informed firm finds it even more difficult to directly benefit from the softened competition. However, when $\partial \pi_{2} / \partial \tau>0$ (i.e., firm 2 benefits from reduced information asymmetry), firm 1 is willing to sell its consumer data to firm 2 as long as $\partial \pi_{i} / \partial \tau+\partial \pi_{2} / \partial \tau>0$ (i.e., the total profit of the two firms increases with reduced information asymmetry). Proposition 7 summarizes firm 1's strategies of consumer data sharing:

Proposition 7: (a) Firm 1 never gives away its consumer data to firm 2 for free. (b) When $p_{h} \leq(2)^{1 / 2} / 2$ or $\tau \geq \tau_{l}$, firm 1 never sells its consumer data to firm 2 . When $p_{h}>(2)^{1 / 2} / 2$ and $\tau<\tau$, firm 1 sells its consumer data to firm 2 to achieve $\tau_{r}$. Firm 1 charges a price of $\pi_{2}\left(\tau_{1}\right)-\pi_{2}(\tau)$ for the consumer data

Although firm 1 has no incentive to share its consumer data for free, Proposition 7 shows that it may sell its consumer data to firm 2 (i.e., paid sharing) under certain circumstances. We find that the total profit of the firms becomes higher if firm 1 shares a bit more data with firm 2 when two conditions hold. First, the likelihood for firm 1 to draw $S=h$ is high enough (i.e., $\mathrm{p}_{\mathrm{h}}>$ $(2)^{1 / 2} / 2$ ). Second, the level of information asymmetry between the firms is high enough (i.e., $\tau<\tau_{1}$ ). Figure 5 illustrates firm 1's sharing decision given $\mathrm{p}_{h}$ and $\tau$. 
Proposition 7 indicates the importance of consumer data exchanges. Consumer data exchanges, such as BlueKai and eXelate, provide marketplaces for individual data owners to directly sell and buy consumer data with each other. Our analysis shows that in the competition with target advertising, the better-informed firm has the incentive to sell its consumer data (i.e., paid sharing). In this regard, the emergence of consumer data exchanges meets the needs of consumer data sharing in target advertising.

Propositions 6 and 7 also provide insights on another important strategic decision - the degree of consumer data sharing. The total profit of the two firms is maximized when $\tau=\tau_{1}$. When $\tau=\tau_{1}$, the firms' competition is the least intense, as shown in Proposition 5, and the total profit of both firms reaches the highest level. Since $\tau_{1}<1$, firm 1 never sells all of its consumer data to the competitor. Otherwise, there is no information asymmetry and the firm competition becomes more intense, eroding the firms' profits. Firm 1 sells only part of its consumer data to maintain an appropriate level of information asymmetry (i.e., let $\tau=\tau_{1}$ ). The price that firm 1 charges is equal to the increase of firm 2's profit, that is, $\pi_{2}\left(\tau_{1}\right)-\pi_{2}(\tau)$. Proposition 8 indicates how the optimal degree of data sharing $\mathrm{t}_{1}$ changes with $\mathrm{p}_{h}$ :

Proposition 8: The optimal degree of consumer data sharing is increasing in $p_{h}$, that is, $\partial \tau_{l} / \partial p_{h}>0$, when $\tau_{l}>0$.

Proposition 8 shows that when it is more likely for firm 1 to draw a high signal from its consumer data (i.e., $p_{h}$ is higher), firm 1 is willing to sell more data to firm 2 . Reducing information asymmetry may dampen the advertising competition. The dampening effect of reduced information asymmetry is more prominent when firm 1 is more likely to receive a high signal $S=h$. Therefore, firm 1 is willing to sell more consumer data when $p_{h}$ is larger. This result generates a positive implication about data selling - when the firms find the consumer market good, they are willing to share more data through paid sharing.

\section{Discussion and Conclusion}

This paper uses a common-value all-pay auction framework to examine the competition between firms using target advertising. The firms differ in their information about the consumer value. The study considers whether the better-informed firm is willing to share its consumer data with the less-informed firm. The existing marketing literature $[9,24]$ largely focuses on the competition in which firms provide differentiated products and consumers have heterogeneous brand preferences. This study, in contrast, examines the competition in which firms provide identical products and consumers have no brand preference. This setting better captures the ecommerce competition using online consumer behavioral data that mainly reflects consumers' purchase intent on products rather than brands. The study shows that even when firms compete head-to-head for the same consumers, reducing information asymmetry between the firms may still soften the competition. In addition, the finding suggests that the better-informed firm is not willing to give away its consumer data for free. However, it has the incentive to sell the information at a price. The insights generated from this study help explain why consumer data sharing occurs even between homogeneous firms that compete head-to-head.

The findings of this study complement the existing literature on interfirm sharing of consumer data. As firms collect more consumer data over time, firms are able to better distinguish between loyal consumers and comparison shoppers. Prior studies (e.g., [9, 24]) 
suggest that information sharing benefits competing firms by inducing them to compete less aggressively on each other's loyal customers. These studies also suggest that information sharing intensifies the competition on comparison shoppers when firms can accurately distinguish comparison shoppers from loyal consumers. Our study shows that information sharing may also soften the firms' competition on shoppers. An important managerial implication is that firms can adopt different strategies to share the data about loyal customers and the data about comparison shoppers.

Another interesting finding of this study is that despite their information difference, the better-informed firm and the less-informed firm spend the same amount on average in target advertising on a consumer. In other words, better information does not help the better-informed firm save the cost of advertising in competition. Instead, better information improves the effectiveness of target advertising. The better-informed firm can use its information to focus its spending on the more promising consumers. As a result, the better-informed firm's expected profit from individual targeting is higher than that of the less-informed firm.

The findings of this study also help justify the emerging business models of online consumer data exchanges. Our analysis shows that when firms compete in target advertising, the better-informed firm may be willing to sell its consumer data to its competitor. Consumer data exchanges provide trading platforms or marketplaces for firms to trade consumer data. When firms are willing to buy/sell consumer data, they have the incentive to join consumer data exchanges. Firms will eventually benefit from such data trading in their advertising competition.

The finding on consumer data sharing in this study suggests that the trade of consumer data can be influenced by the condition of the consumer market. For example, the results suggest that when the better-informed firm is less likely to draw a good signal about the consumer value, consumer data sharing is less likely to happen. However, when the better-informed firm is more likely to draw a good signal, it may sell its data. In this regard, when the market conditions are good (e.g., the majority of consumers are valuable consumers and it is, in general, more likely for a firm to draw good signals from its consumer data), the selling of consumer data is more likely to occur and the better-informed firm is willing to sell more data.

The study provides opportunities for future research. First, firms often share consumer data through third-party organizations such as customer data intermediaries [31] and trade associations [39]. The role of these third-party organizations in sharing individual-level data about consumers is worth further study. Second, this paper focuses on the case where the betterinformed firm has more data on the same consumer. Future studies could examine the case that the better-informed firm's data does not completely encompass the less informed firm's data. Lastly, future studies could investigate the privacy issues and policy implications on consumer data sharing.

Notes

1. This assumption is used to reduce the complexity of the analysis. The insights in this paper hold for the much more complex case where firm 1 draws from a valuable consumer a high signal with probability y and a low signal with a positive probability 1 $\psi$, where $\psi>\zeta$.

2. A less likely case is that although firms target the same consumer, they receive completely independent signals about the same consumer. This analysis is left for future research. 
3. Chen [6] considers three possible ways to share consumer data. The third option is that firms exchange consumer data with one another. In our paper, this option is not applicable because firm 1's consumer data is richer than firm 2's, and such an exchange cannot improve firm 1's data.

\section{Reference}

1. Amann, E., and Leininger, W. Asymmetric all-pay auctions with incomplete information: The two-player case. Games and Economic Behavior, 14, 1 (1996), 1-18.

2. Angwin, J. The Web's new gold mine: Your secrets. Wall Street Journal, July 30, 2010 (available at http://online.wsj.com/article/SB1000142405274870394090457539507351298 9404.html).

3. Banerjee, P. Common value auctions with asymmetric bidder information. Economics Letters, 88, 1 (2005), 47-53.

4. Bhargava, H.K., and Choudhary, V. Economics of an information intermediary with aggregation benefits. Information Systems Research, 15, 1 (2004), 22-36.

5. Bult, J.R., and Wansbeek, T. Lists and database (mailing list versus database marketing). Catalog Age, August 1, 1996.

6. Chen, F. Information sharing and supply chain coordination. In S.C. Graves and A.G. de Kok (eds.), Handbooks in Operations Research and Management Science, Volume 11: Supply Chain Management: Design, Coordination and Operation. Amsterdam: Elsevier, 2003, pp. 341-421.

7. Chen, J., and Stallaert, J. An economic analysis of online advertising using behavioral targeting. MIS Quarterly (2013), forthcoming.

8. Chen, Y., and Iyer, G. Consumer addressibility and customized pricing. Marketing Science, 21, 2 (2002), 197-208.

9. Chen, Y.; Narasimhan, C.; and Zhang, Z.J. Individual marketing with imperfect targetability. Marketing Science, 20, 1 (2001), 23-41.

10. Choudhary, V.; Ghose, A.; Mukhopadhyay, T.; and Rajan, U. Personalized pricing and quality differentiation. Management Science, 51, 7 (2005), 1120-1130.

11. Dewan, R., and Freimer, M. Consumers prefer bundled add-ins. Journal of Management Information Systems, 20, 2 (Fall 2003), 99-111.

12. Engelbrecht-Wiggans, R.; Milgrom, P.R.; and Weber, R.J. Competitive bidding and proprietary information. Journal of Mathematical Economics, 11, 2 (1983), 161-169.

13. Esteban, L.; Gil, A.; and Hernández, J.M. Information advertising and optimal targeting in a monopoly. Journal of Industrial Economics, 49, 2 (2001), 161-180.

14. Gal-Or, E. Information transmission-Cournot and Bertrand equilibria. Review of Economic Studies, 53, 1 (1986), 85-92.

15. Geng, X.; Stinchcombe, M.B.; and Whinston, A.B. Bundling information goods of decreasing value. Management Science, 51, 4 (2005), 662-667.

16. Ha, A.; Tong, S.; and Zhang, H. Sharing demand information in competing supply chains with production diseconomies. Management Science, 57, 3 (2011), 566-581.

17. Hallerman, D. Audience ad targeting: Data and privacy issues. eMarketer Report, February 2010. 
18. Hausch, D.B. An asymmetric common-value auction model. RAND Journal of Economics, 18, 4 (Winter 1987), 611-621.

19. Hauswald, R., and Marquez, R. Competition and strategic information acquisition in credit markets. Review of Financial Studies, 19, 3 (Fall 2006), 967-1000.

20. Hui, W.; Yoo, B.; and Tam, K.T. The optimal number of versions: Why does Goldilocks pricing work for information goods? Journal of Management Information Systems, 24, 3 (Winter 2007-8), 167-191.

21. Iyer, G.; Soberman, D.; and Villas-Boas, J.M. The targeting of advertising. Marketing Science, 24, 3 (2005), 461-476.

22. Li, L. Information sharing in a supply chain with horizontal competition. Management Science, 48, 9 (2002) 1196-1212.

23. Li, L., and Zhang, H. Confidentiality and information sharing in supply chain coordination. Management Science, 54, 8 (2008), 1467-1481.

24. Liu, Q., and Serfes, K. Customer information sharing among rival firms. European Economic Review, 50, 6 (2006), 1571-1600.

25. Liu, Y., and Zhang, Z.J. The benefits of personalized pricing in a channel. Marketing Science, 25, 1 (2006), 97-105.

26. McWilliams, G. Minding the store: Analyzing customers, BestBuy decides not all are welcome. Wall Street Journal, November 8, 2004 (available at http://online.wsj.com/article/ 0,,SB109986994931767086,00.html).

27. Measuring consumer intent actions across the Web. Bluekai Pulse, September 2009 (available at www.bluekai.com/pulse/112009.pdf).

28. Mehra, A.; Bala, R.; and Sankaranarayanan, R. Competitive behavior-based price discrimination for software upgrades. Information Systems Research, 23, 1 (2012), 6074.

29. Milgrom, P.R., and Weber, R.J. The value of information in a sealed-bid auction. Journal of Mathematical Economics, 10, 1 (1982), 105-114.

30. Pagano, M., and Jappelli, T. Information sharing in credit markets. Journal of Finance, 48, 5 (1993), 1693-1718.

31. Pancras, J., and Sudhir, K. Optimal marketing strategies for a customer data intermediary. Journal of Marketing Research, 44, 4 (2007), 560-578.

32. Parreiras, S., and Rubinchik, A. Contests with three or more heterogeneous agents. Games and Economic Behavior, 68, 2 (2010), 703-715.

33. Roy, S. Strategic segmentation of a market. International Journal of Industrial Organization, 18, 8 (2000), 1279-1290.

34. Shaffer, G., and Zhang, Z.J. Competitive coupon targeting. Marketing Science, 14, 4 (1995), 395-416.

35. Steel, E., and Angwin, J. On the web's cutting edge, anonymity in name only. Wall Street Journal, August 4, 2010 (available at http://online.wsj.com/article/SB100014240527487032 94904575385532109190198.html).

36. Taylor, C.R. Consumer privacy and the market for customer information. RAND Journal of Economics, 35, 4 (Winter 2004), 631-650.

37. Villas-Boas, J.M. Sleeping with the enemy: Should competitors share the same advertising agency? Marketing Science, 13, 2 (1994), 190-202. 
38. Vives, X. Duopoly information equilibrium: Cournot and Bertrand. Journal of Economic Theory, 34, 1 (1984), 71-94.

39. Vives, X. Trade association disclosure rules, incentives to share information, and welfare. RAND Journal of Economics, 21, 3 (Autumn 1990), 409-430.

\section{Appendix}

Proof of Lemma 1

Since $E[V \mid h] \geq E[V \mid l]$ and $E[V]=p_{h} E[V \mid h]+\left(1-p_{h}\right) E[V \mid l]$, we have

$$
E[V \mid l] \leq E[V] \leq E[V \mid h]
$$

The consumer's expected value given a signal $\tilde{S} \in\{\tilde{h}, \tilde{l}\}$ can be represented by

$$
E[V \mid \tilde{S}]=\rho_{h \mid \tilde{S}} E[V \mid h]+\rho_{l \mid \tilde{S}} E[V \mid l]
$$

Where $\rho_{h \mid \tilde{s} \text { and }} \rho_{l \mid \tilde{s}}$ are posterior probabilities. Based on Bayes's rule, there are

$$
\rho_{S \mid \tilde{S}}=\frac{p_{\tilde{S} \mid S} p_{S}}{p_{\tilde{S}}}, S \in\{h, l\}, \tilde{S} \in\{\tilde{h}, \tilde{l}\},
$$

Where $p_{\tilde{S}}=p_{\tilde{S} \mid h} p_{h}+p_{\tilde{S} \mid l} p_{l^{*}}$ Since $E[V \mid h] \geq E[V \mid l]$,we have

$$
E[V \mid l] \leq E[V \mid \tilde{h}] \leq E[V \mid h] \text { and } E[V \mid l] \leq E[V \mid \tilde{l}] \leq E[V \mid h]
$$

From Equation (1), we have

$$
\rho_{h \mid \tilde{h}}=\frac{(1+\tau) p_{h}}{(1+\tau) p_{h}+(1-\tau) p_{l}}, \rho_{h \mid \tilde{l}}=\frac{(1-\tau) p_{h}}{(1-\tau) p_{h}+(1+\tau) p_{l}} .
$$

Comparing $\rho_{h \mid \tilde{h} \text { and }} \rho_{h \mid \tilde{l}}$, we get $\rho_{h \mid \tilde{h}} \geq \rho_{h \mid \tilde{I}^{*}}$ We therefore have $E[V \mid \tilde{h}] \geq E[V \mid \tilde{l}]$. Also, since $E[V]=p_{\tilde{h}} E[V \mid \tilde{h}]+p_{\tilde{l}} E[V \mid \tilde{l}]$, we get

$$
E[V \mid \tilde{l}] \leq E[V] \leq E[V \mid \tilde{h}] .
$$


Combining Equations (A1), (A2), and (A3), we have

$$
E[V \mid l] \leq E[V \mid \tilde{l}] \leq E[V] \leq E[V \mid \tilde{h}] \leq E[V \mid h]
$$

Q.E.D.

Proof of Proposition 1

Let $\pi_{i}\left(x_{i} \mid S\right)$ denote firm 1's expected profit of spending $\mathrm{x}_{1}$ in target advertising when $S \in\{h, l\}$.

Let $\pi_{2}\left(x_{2} \mid \tilde{S}\right)$ denote firm 2's expected profit of spending $\mathrm{x}_{2}$ in target advertising when $\tilde{S} \in\{\tilde{h}, \tilde{l}\}$.

Let $\bar{x}_{1 S}, \underline{x}_{1 s}$ denote the upper bound and lower bound of firm 1's advertising spendings, respectively, given $S$. Let $\bar{x}_{2 \tilde{s}}, \underline{x}_{2 \tilde{s}}$ denote firm 2's upper bound and lower bound of advertising spending, respectively, given $\tilde{S}$.

Lemma A1: $\underline{x}_{1 l}=\bar{x}_{1 l}=0$.

Proof: When firm 1 has $S=1$, it expects that the value of the consumer is $E[V \mid l]=0$. Therefore, firm 1 will not spend more than zero, that is, $\underline{x}_{1 l}=\bar{x}_{1 l}=0$. Firm 1 's expected profit given $S=1$ is zero, that is, $\pi_{1}(l)=0$. Q.E.D.

The upper and lower bounds of the firms' advertising spendings satisfy the following conditions: (1) $\underline{x}_{1 S} \geq 0, \underline{x}_{2 \tilde{S}} \geq 0$; (2) $\bar{x}_{1 S} \leq E[V \mid S], \bar{x}_{2 \tilde{S}} \leq E[V \mid \tilde{S}]$; and (3) $\bar{x}_{1 h}=\max \left\{\bar{x}_{2 \tilde{h}}, \bar{x}_{2 \tilde{l}}\right\}$

Since $E[V \mid l]=0$, the firms' profit functions can be written as

$$
\begin{aligned}
\pi_{1}\left(x_{1} \mid h\right)= & p_{\tilde{h} \mid h} F_{2}\left(x_{1} \mid \tilde{h}\right) E[V \mid h]+p_{\tilde{l} \mid h} F_{2}\left(x_{1} \mid \tilde{l}\right) E[V \mid h]-x_{1} \\
& \pi_{2}\left(x_{2} \mid \tilde{h}\right)=\rho_{h \mid \tilde{h}} F_{1}\left(x_{2} \mid h\right) E[V \mid h]-x_{2} \\
& \pi_{2}\left(x_{2} \mid \tilde{l}\right)=\rho_{h \mid \tilde{l}} F_{1}\left(x_{2} \mid h\right) E[V \mid h]-x_{2} .
\end{aligned}
$$

Lemma A2: $\hat{x} \triangleq \underline{x}_{2 \hat{h}}=\bar{x}_{2 \tilde{I}}$.

Proof: Suppose $\underline{x}_{2 \tilde{h}}<\bar{x}_{2 \tilde{l}}$. The supports of $F_{2}(x \mid \tilde{h})$ and $F_{2}(x \mid \tilde{l})$ overlap on $\left[\underline{x}_{2 \tilde{h}}, \bar{x}_{2 \tilde{l}}\right]$. In the mixedstrategy equilibrium, when firm 2 has $S=\tilde{h}$, its expected profit of spending $x_{2} \in\left[\underline{x}_{2 \tilde{h}}, \bar{x}_{2 \tilde{l}}\right]$ in advertising is constant; similarly, when firm 2 has $S=\tilde{l}$, its expected profit of spending $x_{2} \in\left[\underline{x}_{2 \tilde{h}}, \bar{x}_{2 \tilde{l}}\right]$ in advertising is constant. Therefore, the value $\pi_{2}\left(x_{2} \mid \tilde{h}\right)-\pi_{2}\left(x_{2} \mid \tilde{l}\right)$ should be constant. However, 


$$
\begin{gathered}
\pi_{2}\left(x_{2} \mid \tilde{h}\right)-\pi_{2}\left(x_{2} \mid \tilde{l}\right)= \\
\rho_{h \mid \tilde{h}} F_{1}\left(x_{2} \mid h\right) E[V \mid h]-x_{2}-\left(\rho_{h \mid \tilde{I}} F_{1}\left(x_{2} \mid h\right) E[V \mid h]-x_{2}\right) \\
=\left(\rho_{h \mid \tilde{h}}-\rho_{h \mid \tilde{l}}\right) F_{1}\left(x_{2} \mid h\right) E[V \mid h] .
\end{gathered}
$$

Since $\rho_{h \mid \tilde{h}}>\rho_{h \mid l}, \pi_{2}\left(x_{2} \mid \tilde{h}\right)-\pi_{2}\left(x_{2} \mid \tilde{l}\right)$ is constant only if $F_{1}\left(x_{2} \mid h\right)=0$ on $x_{2} \in\left[\underline{x}_{2 \tilde{h}}, \bar{x}_{2 \tilde{l}}\right]$. The condition suggests that firm 1's lower bound of its CDF when $S=h$ is not lower than $\bar{x}_{2 i}$. Therefore, we cannot have $\underline{x}_{2 \dot{h}}<\bar{x}_{2 \tilde{i}}$.

Suppose $\underline{x}_{2 \tilde{h}}>\bar{x}_{2 \tilde{l}}$. There is a gap between the supports for $F_{2}(x \mid \tilde{h})$ and $F_{2}(x \mid \tilde{l})$. As a result, firm 1 will never spend a value in $\left(\bar{x}_{2 \tilde{i}}, \underline{x}_{2 \tilde{h}}\right)$. Firm 1 will not spend at $\underline{m}_{2 \tilde{h}}$ either. This is because $\underline{x}_{2 \tilde{h}}$ and $\bar{x}_{2 \hat{I}}$ lead to the same probability of winning but firm 1 pays more at $\underline{x}_{2 \hat{h}^{*}}$ Consequently, firm 2 never spends $\underline{m}_{2 \tilde{h}}$ either, which contradicts the fact that $\underline{x}_{2 \tilde{h}}$ is firm 2's lower bound of marketing spending when it receives $\tilde{S}=\tilde{h}$.

To summarize, we cannot have either $\underline{x}_{2 \tilde{h}}<\bar{x}_{2 \tilde{i}}$ or $\underline{x}_{2 \tilde{h}}>\bar{x}_{2 \tilde{i}} \cdot$ The only possibility is $\underline{x}_{2 i}=\bar{x}_{2 i} \cdot$ We define $\hat{x} \stackrel{\hat{x}}{=} \underline{x}_{2 \tilde{h}}=\bar{x}_{2 \tilde{i}}$. Q.E.D.

\section{Lemma A3: $\hat{x} \geq \underline{x}_{1 h}$.}

Proof: Suppose $\bar{x}_{2 \tilde{h}}=\bar{x}_{1 h^{\prime}}$. We define $\bar{x}_{1} \triangleq \bar{x}_{2 \tilde{h}}=\bar{x}_{1 h}$. We next prove that firms put no mass point at $\bar{x}_{1}$. Suppose that firm 2 puts a mass point at $\bar{x}_{1}$. Firm 1 has an incentive to put a mass point at $\bar{x}_{1}+\varepsilon$ to beat firm 2 and win the consumer. Then $\bar{x}_{1}$ will not be the upper bounds of the CDFs. Therefore, we cannot have firm 2 putting a mass point at $\bar{x}_{1}$.

Suppose firm 2 does not have a mass point at $\bar{x}_{1}$ but firm 1 does. If $\bar{x}_{1}<E[C \mid \tilde{h}]$ firm 2 has an incentive to put a mass point at $\bar{x}_{1}+\varepsilon$. Then $\bar{x}_{1}$ will not be the upper bounds of the CDFs. If $\bar{x}_{1}=E[C \mid \tilde{h}]$ then firm 2's expected profit when spending $\bar{x}_{1}$ is

$$
\pi_{2}\left(\bar{x}_{1} \mid \tilde{h}\right)=\rho_{h \mid \tilde{h}} F_{1}\left(\bar{x}_{1} \mid h\right) E[V \mid h]-\bar{x}_{1}<\rho_{h \mid \tilde{h}} E[V \mid h]-\bar{x}_{1}=0
$$

Therefore, we cannot have firm 1 putting a mass point at $\bar{x}_{1}$ either. Q.E.D.

In summary, there is no mass point at $\bar{x}_{1}$ for both firms' advertising spending distribution.

So far, we can conclude that (1) the support for $F_{2}(x \mid \tilde{l})$ is $\left[\underline{x}_{2 i}, \hat{x}\right],(2)$ the support for $F_{2}(x \mid \tilde{h})$ is $\left[\hat{x}, \bar{x}_{1}\right]$, and (3) the support for $F_{1}(x \mid h)$ is $\left[\underline{x}_{1 h}, \bar{x}_{1}\right]$.

Lemma A5: $\pi_{2}(x \mid \tilde{l})=0$.

Proof: Suppose $\pi_{2}(x \mid \tilde{l})>0$. From Equation (A6), we have 


$$
\pi_{2}\left(\underline{x}_{2 \tilde{l}} \mid \tilde{l}\right)=\rho_{h \mid \tilde{l}} F_{1}\left(x_{2 \tilde{l}} \mid h\right) E[V \mid h]-\underline{x}_{2 \tilde{l}}>0 .
$$

To satisfy $\pi_{2}\left(\underline{m}_{2 i} \mid \tilde{l}\right)>0$, we must have $F_{1}\left(\underline{x}_{2 l} \mid h\right)>0 . F_{1}\left(\underline{x}_{2 i} \mid h\right)$ is positive only when either of the following cases is true: (1) $\underline{x}_{1 h}<\underline{x}_{2 \tilde{l}}$ or (2) $\underline{x}_{1 h}=\underline{x}_{2 i}$ and firm 1 has a mass point at $\underline{x}_{2 \tilde{l}}$. Q.E.D.

We next show that the first case, $\underline{x}_{1 h}=\underline{x}_{2 \tilde{l}}$, and firm 1 has a mass point at $\underline{x}_{2 \tilde{l}}$ cannot be true. Since firms cannot both have a mass point at a boundary simultaneously in equilibrium, if firm 1 has a mass point at $\underline{x}_{1 h}=\underline{x}_{2 i}$;, we must have $F_{2}\left(\underline{x}_{1 h} \mid \tilde{h}\right)=0$ and $F_{2}\left(\underline{x}_{1 h} \mid \tilde{l}\right)$. Considering Equation (A4), we have

$$
\pi_{1}\left(\underline{x}_{1 h} \mid h\right)=\mathrm{p}_{\tilde{h} \mid h} F_{2}\left(\underline{x}_{1 h} \mid \tilde{h}\right) E[V \mid h]+\mathrm{p}_{\tilde{l} \mid h} F_{2}\left(\underline{x}_{1 h} \mid \tilde{l}\right) E[V \mid h]-\underline{x}_{1 h} .
$$

If $F_{2}\left(\underline{x}_{1 h} \mid \tilde{h}\right)=0$ and $F_{2}\left(\underline{x}_{1 h} \mid \tilde{l}\right)=0, \pi_{1}\left(\underline{x}_{1 h} \mid h\right)$ is nonpositive. However, this cannot be true as we proved above. Therefore, the second case cannot be true. Q.E.D.

In conclusion, firm 2 must make a zero expected profit when $\tilde{S}=\tilde{l}$, that is, $\pi_{2}(x \mid \tilde{l})=0$

We therefore can develop the following conjectures based on Lemma A5:

Conjecture 1: For $x_{2} \in\left[\underline{x}_{2 \tilde{l}}, \hat{x}\right], \pi_{2}\left(x_{2} \mid \tilde{l}\right)=0$ and for $x_{2} \in\left[\hat{x}, \bar{x}_{1}\right], \pi_{2}\left(x_{2} \mid \tilde{h}\right)=0$.

Conjecture 2: For $x_{2} \in\left[\underline{x}_{2 \tilde{l}}, \hat{x}\right], \pi_{2}\left(x_{2} \mid \tilde{l}\right)=0$ and for $x_{2} \in\left[\hat{x}, \bar{x}_{1}\right], \pi_{2}\left(x_{2} \mid \tilde{h}\right) \geq 0$.

We first consider Conjecture 1 and derive the firms' advertising spending distributions. From $\pi_{2}(x \mid \tilde{h})=\rho_{h \mid \tilde{h}} F_{1}(x \mid h) E[V \mid h]-x=0$, we have

$$
F_{1}(x \mid h)=\frac{x}{\rho_{h \mid \tilde{h}} E[V \mid h]}
$$

Lemma A6: $\bar{x}_{1}=E[V \mid \tilde{h}]$.

Proof: By Lemma A4 and Equation (A7), we have $F_{1}\left(\bar{x}_{1} \mid h\right)=\bar{x}_{1} / \rho_{h \mid \tilde{l}_{1}} E[V \mid h]=1$. Therefore, $\bar{x}_{1}=\rho_{h \mid \tilde{h}} E[V \mid h]=E[V \mid \tilde{h}]$. Q.E.D.

$$
\text { Lemma A7: } \hat{x}=\underline{x}_{2 \tilde{l}}=\underline{x}_{2 \tilde{h}}=\underline{x}_{1 h}=0 \text { and }\left.F_{1}(x \mid h)\right|_{x=0}=0 \text {. }
$$

Proof: Suppose $\underline{x}_{1 h}>0$. From Lemma A3, we must have ${ }^{\hat{x} \geq \underline{x}_{1 h}>0}$. From Equations (A6) and (A7), we have 


$$
\pi_{2}(\hat{x} \mid \tilde{l})=\rho_{h \mid \tilde{l}} \frac{\hat{x}}{\rho_{h \mid \tilde{h}} E[V \mid h]} E[V \mid h]-\hat{x} .
$$

Because $\rho_{h \mid \tilde{l}}<\rho_{h \mid \tilde{h}}$, we have $\pi_{2}(\hat{x} \mid \tilde{l})<0$. This contradicts the fact that $\pi_{2}(\hat{x} \mid \tilde{l}) \geq 0$. To ensure that $\pi_{2}(\hat{x} \mid \tilde{l})<0$, we must have $\hat{x}=0$. Therefore, we have $\underline{x}_{1 h}=\underline{x}_{2 \hat{h}}=\bar{x}_{2 \hat{l}}=0$. It is easy to verify that $F_{1}\left(\underline{x}_{1 h} \mid h\right)=1$. In other words, $F_{1}(x \mid h)$ has no mass point at $\underline{x}_{1 h}$. We conclude that firm 2 spends zero when it has $\mathrm{S}=\tilde{l}$, that is,

$$
F_{2}(x \mid \tilde{l})= \begin{cases}0 & x<0 \\ 1 & x \geq 0\end{cases}
$$

Q.E.D.

We can rewrite firm 1's expected profit given any advertising spending as

$$
\pi_{1}(x \mid h)=p_{\tilde{h} \mid h} F_{2}(x \mid \tilde{h}) E[V \mid h]+p_{\tilde{l} \mid h} E[V \mid h]-x .
$$

By Lemmas A4 and A6, we can conclude that its profit is $\pi_{1}\left(x_{1} \mid h\right)=E[V \mid h]-E[V \mid \tilde{h}]$ when firm 1 receives $S=h$. Based on Equation (A8), we have

$$
F_{2}(x \mid \tilde{h})=\frac{\left(\rho_{l \mid \tilde{h}}-\rho_{\tilde{l} \mid h}\right) E[V \mid h]+x}{p_{\tilde{h} \mid h} E[V \mid h]} .
$$
follows:

In this case, the equilibrium strategies of firms' competition can be summarized as

(a) When $\mathrm{S}=1$, firm 1 spends zero in target advertising (i.e., no targeting). When $S=h$, firm 1 spends in target advertising according to

$$
F_{1}(x \mid h)=\frac{x}{\rho_{h \mid \tilde{h}} E[V \mid h]}, x \in[0, E[V \mid \tilde{h}]] \text {, }
$$

(b) When $\tilde{S}=\tilde{l}$, firm 2 spends zero in target advertising. When $S=\tilde{h}$, firm 2 spends in target advertising according to 


$$
F_{2}(x \mid \tilde{h})=\frac{\left(\rho_{l \mid \tilde{h}}-p_{\tilde{\imath} \mid h}\right) E[V \mid h]+x}{p_{\tilde{h} \mid h} E[V \mid h]}, x \in[0, E[V \mid \tilde{h}]] .
$$

We can verify that the sufficient and necessary condition for the existence of this equilibrium is $p_{h} \leq p_{l}$ Q.E.D.

Proof of Proposition 2

We consider the case $p_{h}>p_{l}$. We next show that there exist $\underline{x}, \hat{x}_{\text {, }}$ and $\bar{x}(\bar{x}<E[V \mid \tilde{h}])$ such that in equilibrium, firm 2 randomizes over $[\hat{x}, \bar{x}]$ when it receives $\tilde{S}=\tilde{h}$ and over $[\underline{x}, \hat{x}]$ when it receives $\tilde{S}=\tilde{l}$. Firm 1 randomizes over $[\underline{x}, \bar{x}]$ when it receives $S=h$.

Lemma A5 gives $\pi_{2}\left(x_{2} \mid \tilde{l}\right)$. From $\pi_{2}\left(x_{2} \mid \tilde{l}\right)=\rho_{h \mid i} F_{1}\left(x_{2} \mid h\right) E[V \mid h]-x_{2}=0$, we have

$$
F_{1}(x \mid h)=\frac{x}{\rho_{h \mid \tilde{I}} E[V \mid h]}, x \in[\underline{x}, x] .
$$

From Lemma A4 and the constant profit of the mixed-strategy equilibrium, we have

$$
\begin{gathered}
\pi_{2}\left(x_{2} \mid \tilde{h}\right)=\rho_{h \mid \tilde{h}} F_{1}\left(x_{2} \mid h\right) E[V \mid h]-x_{2}=\rho_{h \mid \tilde{h}} E[V \mid h]-\bar{x}, x_{1} \in[x, \bar{x}], \\
\pi_{1}\left(x_{1} \mid h\right)=p_{\tilde{h} \mid h} F_{2}\left(x_{1} \mid \tilde{h}\right) E[V \mid h]+p_{\tilde{l} \mid h} E[V \mid h]-x_{1}=E[V \mid h]-\bar{x}, x_{1} \in[x, \bar{x}],
\end{gathered}
$$

And

$$
\pi_{1}(x \mid h)=p_{\tilde{l} \mid h} F_{2}(x \mid \tilde{l}) E[V \mid h]-x=E[V \mid h]-\bar{x}, x_{1} \in[\underline{x}, x]
$$

We therefore can derive 


$$
\begin{gathered}
F_{1}(x \mid h)=\frac{\rho_{h \mid \tilde{h}} E[V \mid h]-\bar{x}+x}{\rho_{h \mid \tilde{h}} E[V \mid h]}, x \in[x, \bar{x}] \\
F_{2}(x \mid \tilde{h})=\frac{p_{\tilde{h} \mid h} E[V \mid h]-\bar{x}+x}{p_{\tilde{h} \mid h} E[V \mid h]}, x \in[x, \bar{x}] \\
F_{2}(x \mid \tilde{l})=\frac{E[V \mid h]-\bar{x}+x}{p_{\tilde{l} \mid h} E[V \mid h]}, x \in[\underline{x}, x] .
\end{gathered}
$$

In the mixed-strategy equilibrium, we must have $\pi_{1}(\hat{x} \mid h)=\pi_{1}(\bar{x} \mid h)$ and $\pi_{2}(\hat{x} \mid \tilde{h})=\pi_{2}(\bar{x} \mid \tilde{h})$, therefore we can derive the following conditions:

$$
\begin{gathered}
p_{\tilde{l} \mid h} E[V \mid h]-\hat{x}=E[V \mid h]-\bar{x} \\
\rho_{h \mid \tilde{h}} F_{1}(\hat{x} \mid h) E[V \mid h]-\hat{x}=\rho_{h \mid \tilde{h}} E[V \mid h]-\bar{x},
\end{gathered}
$$

Where $F_{1}(\hat{x} \mid h)=\hat{x} / \rho_{h l i} E[V \mid h]$ from Equation (A10). Solving Equations (A14) and (A15), we get

$$
\hat{x}=\rho_{h \mid \tilde{I}}\left(1-\frac{p_{\tilde{h}}}{p_{h}}\right) E[V \mid h], \bar{x}=\left(p_{\tilde{h} \mid h}+\rho_{h \mid \tilde{I}}\left(1-\frac{p_{\tilde{h}}}{p_{h}}\right)\right) E[V \mid h] .
$$

Lemma A8: $\underline{x}=0, F_{2}(0 \mid \tilde{l})>0$, and $F_{1}(0 \mid h)=0$.

Proof: From Equations (A10) and (A13), we have

1. When $\mathrm{x}_{1}=0, \mathrm{~F}_{1}\left(\mathrm{x}_{1} \mid h\right)=0$ and when $\mathrm{x}_{2}=0, F_{2}\left(x_{2} \mid \tilde{l}\right)>0$;

2. If $\underline{x}>0$, we have $F_{1}(\underline{x} \mid h)>0$ and $F_{2}(\underline{x} \mid \tilde{l})>0$. This cannot be true because firms cannot both have a mass point at the lower bound. Therefore, in equilibrium, $\underline{x}=0,\left.F_{1}(x \mid h)\right|_{x=0}=0$ and $\left.F_{2}(x \mid \tilde{l})\right|_{x=0}>0$. Only firm 2 has a mass point at the lower bound. Q.E.D. follows:

When $p_{h}>p_{l}$, the equilibrium strategies of firms' competition can be summarized as 
(a) When $S=l$, firm 1 spends zero in target advertising. When $S=h$, firm 1 spends in target advertising according to

$$
F_{1}(x \mid h)=\left\{\begin{array}{cc}
\frac{x}{\rho_{h \mid \tilde{I}} E[V \mid h]} & x \in[0, x] \\
\frac{\rho_{h \mid \tilde{h}} E[V \mid h]-\bar{x}+x}{\rho_{h \mid \tilde{h}} E[V \mid h]} & x \in[x, \bar{x}]
\end{array}\right.
$$

(b) When $\tilde{S}=\tilde{l}$, firm 2 spends in target advertising according to

$$
F_{2}(x \mid \tilde{l})=\frac{E[V \mid h]-\bar{x}+x}{p_{\tilde{l} \mid h} E[V \mid h]}, x \in[0, x] .
$$

When $\tilde{S}=\tilde{h}$, firm 2 spends in target advertising according to

$$
F_{2}(x \mid \tilde{h})=\frac{p_{\tilde{h} \mid h} E[V \mid h]-\bar{x}+x}{p_{\tilde{h} \mid h} E[V \mid h]}, x \in[x, \bar{x}] .
$$

We can verify that the sufficient and necessary condition for the existence of the second equilibrium is $p_{l}<p_{h}$

Proof of Proposition 3

When $p_{h} \leq p_{l}$, firm 1's expected advertising spendings are

$$
\begin{gathered}
E\left[x_{1} \mid l\right]=0, E\left[x_{1} \mid h\right]=\int_{0}^{E[V \mid \tilde{h}]} x d \frac{x}{\rho_{h \mid \tilde{h}} E[V \mid h]}=\frac{1}{2} \rho_{h \mid \tilde{h}} E[V \mid h] . \\
E\left[x_{1}\right]=p_{l} E\left[x_{1} \mid l\right]+p_{h} E\left[x_{1} \mid h\right]=\frac{1}{2} p_{h} \rho_{h \mid \tilde{h}} E[V \mid h] .
\end{gathered}
$$

Firm 2's expected advertising spendings are 


$$
\begin{gathered}
E\left[x_{2} \mid \tilde{l}\right]=0, E\left[x_{2} \mid \tilde{h}\right]=\int_{0}^{E[V \mid \tilde{h}]} x d \frac{\left(\rho_{l \mid \tilde{h}}-p_{\tilde{\imath} \mid h}\right) E[V \mid h]+x}{p_{\tilde{h} \mid h} E[V \mid h]} \\
=\frac{1}{2} \frac{p_{h}}{p_{\tilde{h}}} \rho_{h \mid \tilde{h}} E[V \mid h] \\
E\left[x_{2}\right]=p_{\tilde{l}} E\left[x_{2} \mid \tilde{l}\right]+p_{\tilde{h}} E\left[x_{2} \mid \tilde{h}\right]=\frac{1}{2} p_{h} \rho_{h \mid \tilde{h}} E[V \mid h] .
\end{gathered}
$$

Comparing Equations (A17) and (A19), we have $E\left[x_{1}\right]=E\left[x_{2}\right]$ Comparing the values in Equations (A16) and (A18), we have $0=E\left[x_{2} \mid \tilde{l}\right]=E\left[x_{1} \mid l\right]<E\left[x_{2} \mid \tilde{h}\right] \leq E\left[x_{1} \mid h\right]$.

When $\mathrm{p}_{h}>\mathrm{p}_{l}$, firm 1 's expected advertising spendings are

$$
\begin{gathered}
E\left[x_{1} \mid l\right]=0, E\left[x_{1} \mid h\right]=\int_{0}^{\mathrm{x}} x d \frac{x}{\rho_{h \mid \tilde{I}} E[V \mid h]}+\int_{\hat{x}}^{\bar{x}} x d \frac{\rho_{h \mid \tilde{h}} E[V \mid h]-\bar{x}+x}{\rho_{h \mid \tilde{h}} E[V \mid h]} \\
E\left[x_{1}\right]=p_{l} E\left[x_{1} \mid l\right]+p_{h} E\left[x_{1} \mid h\right]=\frac{p_{h}}{2 E[V \mid h]}\left(\frac{\hat{x}^{2}}{\rho_{h \mid \tilde{l}}}+\frac{\bar{x}^{2}-\hat{x}^{2}}{\rho_{h \mid \tilde{h}}}\right) .
\end{gathered}
$$

Firm 2's expected advertising spending is

$$
\begin{gathered}
E\left[x_{2} \mid \tilde{l}\right]=\int_{0}^{\hat{x}} x d \frac{E[V \mid h]-\bar{x}+x}{p_{\tilde{l} \mid h} E[V \mid h]}, E\left[x_{2} \mid \tilde{h}\right]=\int_{\hat{x}}^{\bar{x}} x d \frac{p_{\tilde{h} \mid h} E[V \mid h]-\bar{x}+x}{p_{\tilde{h} \mid h} E[V \mid h]} \\
E\left[x_{2}\right]=p_{\tilde{l}} E\left[x_{2} \mid \tilde{l}\right]+p_{\tilde{h}} E\left[x_{2} \mid \tilde{h}\right]=\frac{p_{h}}{2 E[V \mid h]}\left(\frac{\hat{x}^{2}}{\rho_{h \mid \tilde{l}}}+\frac{\bar{x}^{2}-\hat{x}^{2}}{\rho_{h \mid \tilde{h}}}\right) .
\end{gathered}
$$

Comparing Equations (A21) and (A23), we have $E\left[x_{1}\right]=E\left[x_{2}\right]$. Comparing the values in Equations (A20) and (A22), we have $0=E\left[x_{1} \mid l\right]<E\left[x_{2} \mid \tilde{l}\right]<E\left[x_{1} \mid h\right]<E\left[x_{2} \mid \tilde{h}\right]$.

In summary, we have that $E\left[x_{1}\right]=E\left[x_{2}\right]$ always holds. When $p_{h} \leq p_{l}, 0=E\left[x_{2} \mid \tilde{l}\right]=$ $E\left[x_{1} \mid l\right]<E\left[x_{2} \mid \tilde{h}\right] \leq E\left[x_{1} \mid h\right]$. When $p_{h}>p_{l}, 0=E\left[x_{1} \mid l\right]<E\left[x_{2} \mid \tilde{l}\right]<E\left[x_{1} \mid h\right]<E\left[x_{2} \mid \tilde{h}\right]$. Q.E.D.

Proof of Proposition 4 
When $p_{h} \leq p_{l}$, firm 1's expected profit is

$$
\pi_{1}=p_{h}(E[V \mid h]-E[V \mid \tilde{h}])=p_{h} \frac{(1-\tau)\left(1-p_{h}\right)}{1-\tau+2 \tau p_{h}} E[V \mid h] .
$$

Firm 2's expected profit is always zero regardless of the signal. Thus, $\pi_{2}=0$.

When $p_{h}>p_{l}$. The firms' expected profits are

$$
\begin{gathered}
\pi_{1}=p_{h}([V \mid h]-\bar{x})=p_{h} \frac{(1-\tau)\left(1-p_{h}\right)}{\left(1+\tau-2 \tau p_{h}\right)} E[V \mid h] \\
\pi_{2}=p_{h}([E \mid \tilde{h}]-\bar{x})=\frac{\left(2 p_{h}-1\right)\left(1-p_{h}\right) \tau(1-\tau)}{1+\tau-2 \tau p_{h}} E[V \mid h] .
\end{gathered}
$$

We can verify that $\pi_{1}>\pi_{2}$ always holds. Q.E.D.

Proof of Proposition 5

When $p_{h} \leq p_{l}$, we have

$$
\begin{gathered}
\frac{\partial E[x]}{\partial \tau}=\frac{p_{h}^{2}\left(1-p_{h}\right)}{\left(1-\tau+2 \tau p_{h}\right)^{2}} E[V \mid h]>0, \\
\frac{\partial E\left[x_{1} \mid h\right]}{\partial \tau}=\frac{p_{h}\left(1-p_{h}\right)}{\left(1-\tau+2 p_{h} \tau\right)^{2}} E[V \mid h]>0,
\end{gathered}
$$

And

$$
\frac{\partial E\left[x_{2} \mid \tilde{h}\right]}{\partial \tau}=\frac{p_{h}^{2}\left(3-4 p_{h}+\left(1-2 p_{h}\right)\right)}{\left(1-\tau+2 p_{h} \tau\right)^{3}} E[V \mid h]>0 .
$$

When $p_{h}>p_{l}$, we have the following formulas: 


$$
\frac{\partial E[x]}{\partial \tau}=-\frac{\left(1-p_{h}\right)\left(\left(2 p_{h}-1\right)^{2} \tau^{2}-2\left(2 p_{h}-1\right) \tau+2 p_{h}^{2}-1\right)}{2\left(1+\tau-2 p_{h} \tau\right)^{2}} E[V \mid h],
$$

$\partial E[x] / \partial \tau \leq 0$ when $\tau \in\left[0, \tau_{1}\right]$ and $\partial E[x] / \partial \tau>0$ when $\tau \in\left(\tau_{1}, 1\right]$, where $\tau_{1}=\max \left\{0,\left(1-\left(2\left(1-p_{h}^{2}\right)\right)^{1 / 2}\right) / 2 p_{h}-1\right\} ;$

$$
\frac{\partial E\left[x_{1} \mid h\right]}{\partial \tau}=-\frac{\left(1-p_{h}\right)\left(\left(2 p_{h}-1\right)^{2} \tau^{2}-2\left(2 p_{h}-1\right) \tau+2 p_{h}^{2}-1\right)}{2 p_{h}\left(1+\tau-2 p_{h} \tau\right)^{2}} E[V \mid h],
$$

$\partial E\left[x_{1} \mid h\right] / \partial \tau \leq 0_{\text {when }} \tau \in\left[0, \tau_{1}\right]_{\text {and }} \partial E\left[x_{\mathrm{r}} \mid h\right] / \partial \tau>0$ when $\tau \in\left(\tau_{1}, 1\right] ;$

$$
\frac{\partial E\left[x_{2} \mid \tilde{h}\right]}{\partial \tau}=-\frac{\left(\left(2 p_{h}-1\right)^{2} \tau^{2}-2\left(2 p_{h}-1\right) \tau-8 p_{h}^{2}+16 p_{h}-7\right)}{4\left(1+\tau-2 p_{h} \tau\right)^{2}} E[V \mid h],
$$

$\partial E\left[x_{2} \mid \tilde{h}\right] / \partial \tau \leq 0$ when $\tau \in\left[0, \tau_{2}\right]$ and $\partial E\left[x_{2} \mid \tilde{h}\right] / \partial \tau>0$ when $\tau \in\left(\tau_{2}, 1\right]$, where $\tau_{2}=\max \left\{0,\left(1-2(2)^{1 / 2}\left(1-p_{h}\right)\right) / 2 p_{h}-1\right\}$;

$$
\frac{\partial E\left[x_{2} \mid \tilde{l}\right]}{\partial \tau}=\frac{(1-\tau)^{2}\left(2 \mathrm{p}_{\mathrm{h}}-1\right)^{2}\left(4 \mathrm{p}_{\mathrm{h}}+2 \mathrm{p}_{\mathrm{h}} \tau-\tau-5\right)}{4\left(1+\tau-2 \mathrm{p}_{h} \tau\right)^{3}} E[V \mid h] .
$$

$\partial E\left[x_{2} \mid \tilde{l}\right] / \partial \tau<0$ as long as $\tau<\left(\left(5-4 p_{h}\right) /\left(2 p_{h}-1\right)\right)>1$. Since $\left(\left(5-4 p_{h}\right) /\left(2 p_{h}-1\right)\right)>1, \partial E\left[x_{2}[\tilde{l}]\right] / \partial \tau<0$ always holds.

We can verify that $\tau_{2} \geq \tau_{1}$ always holds. Q.E.D.

Proof of Proposition 6

When $p_{h} \leq p l$, we have

$$
\frac{\partial \pi_{1}}{\partial \tau}=\frac{-2 p_{h}^{2}\left(1-p_{h}\right)}{\left(1-\tau+2 \tau p_{h}\right)^{2}} E[V \mid h]<0 .
$$

When $p_{h}>p_{l}$, we have the following formulas: 


$$
\begin{gathered}
\frac{\partial \pi_{1}}{\partial \tau}=-\frac{2 p_{h}\left(1-p_{h}\right)^{2}}{\left(1+\tau-2 \tau p_{h}\right)^{2}} E[V \mid h]<0, \\
\frac{\partial \pi_{2}}{\partial \tau}=\left(2 p_{h}-1\right)\left(1-p_{h}\right) \frac{1-2 \tau+\left(2 p_{h}-1\right) \tau^{2}}{\left(1+\tau-2 \tau p_{h}\right)^{2}} E[V \mid h] .
\end{gathered}
$$

$\partial \pi_{2} / \partial \tau \geq 0$ if $\tau \in\left[0, \tau_{3}\right]$ and $\partial \pi_{2} / \partial \tau<0$ if $\tau \in\left(\tau_{3}, 1\right]$ where $\tau_{3}=\left(1-\left(2\left(1-p_{h}\right)\right)^{1 / 2}\right) / 2 p_{h}-1$ Q.E.D.

Proof of Proposition 7

Proposition 6 gives $\partial \pi_{1} / \partial \tau<0$. Therefore, firm 1 never gives its consumer data to firm 2 for free.

When $p_{h} \leq p_{l}$,

$$
\Pi=\pi_{1}=p_{h} \frac{(1-\tau)\left(1-p_{h}\right)}{1-\tau+2 \tau p_{h}} E[V \mid h],
$$

we have $\partial \Pi / \partial \tau=\partial \pi / \partial \tau<0$. Therefore, firm 1 has no incentive to sell its consumer data to firm 2.

When $p_{h}>p_{l}$,

$$
\Pi=\pi_{1}+\pi_{2}=\frac{(1-\tau)\left(1-p_{h}\right)\left(2 p_{h} \tau-\tau+p_{h}\right)}{\left(1+\tau-2 \tau p_{h}\right)} E[V \mid h],
$$

we have

$$
\frac{\partial \Pi}{\partial \tau}=\left(1-p_{h}\right) \frac{\left(2 p_{h}-1\right)^{2} \tau^{2}-2\left(2 p_{h}-1\right) \tau+2 p_{h}^{2}-1}{\left(1+\tau-2 \tau p_{h}\right)^{2}} E[V \mid h] .
$$

$\partial \Pi / \partial \tau \geq 0$ when $\tau \in\left[0, \tau_{1}\right]$ and $\tau \in\left(\tau_{1}, 1\right]$. Firm 1 has an incentive to sell its consumer data to firm 2 to achieve $\tau=\tau_{1}$ when $\tau<\tau_{1}$. Based on Proposition $6, \partial \pi_{2} / \partial \tau \geq 0$ if $\tau \in\left[0, \tau_{3}\right]$. Since $\tau_{1}<\tau_{3}$, firm 2 is willing to purchase the consumer data when $\tau \in\left[0, \tau_{1}\right]$. 
Note $\tau_{1}>0$ when $p_{h}>(2)^{1 / 2} / 2$. In summary, when $p_{h} \leq(2)^{1 / 2} / 2$ or $\tau>\tau_{1}$, firm 1 never shares consumer data with firm 2 . When $p_{h}>(2)^{1 / 2} / 2$ and $\tau<\tau_{1}$, firm 1 has an incentive to sell consumer data with firm 2 and achieve $\tau=\tau_{1}$. Q.E.D.

\section{Proof of Proposition 8}

Based on Proposition 5, we have that $\tau_{1}=\max \left\{0,\left(1-\left(2\left(1-p_{h}^{2}\right)\right)^{1 / 2}\right) / 2 p_{h}-1\right\}$. Differentiating $\left(1-\left(2\left(1-p_{h}^{2}\right)\right)^{1 / 2}\right) / 2 p_{h}-1$ with respect to $p_{h}$, we have $\partial \tau_{1} / \partial p_{h}>0$ when $\tau_{1}>0$. Q.E.D. 